\title{
The potential neuroprotective role of a histone deacetylase inhibitor, sodium butyrate, after neonatal hypoxia-ischemia
}

\author{
Joanna Jaworska ${ }^{\dagger}$, Malgorzata Ziemka-Nalecz ${ }^{\dagger}$, Joanna Sypecka and Teresa Zalewska ${ }^{*}$ (D)
}

\begin{abstract}
Background: Histone deacetylase inhibitor (HDACi), sodium butyrate (SB), has been shown to be neuroprotective in adult brain injury models. Potential explanation for the inhibitor action involves among others reduced inflammation. We therefore anticipated that SB will provide a suitable option for brain injury in immature animals. The aim of our study was to test the hypothesis that one of the mechanisms of protection afforded by SB after neonatal hypoxia-ischemia is associated with anti-inflammatory action. We examined the effect of SB on the production of inflammatory factors including analysis of the microglial and astrocytic cell response. We also examined the effect of SB on molecular mediators that are crucial for inducing cerebral damage after ischemia (transcription factors, HSP70, as well as pro- and anti-apoptotic proteins).

Methods: Seven-day-old rat pups were subjected to unilateral carotid artery ligation followed by 60 min of hypoxia $\left(7.6 \% \mathrm{O}_{2}\right)$. SB $(300 \mathrm{mg} / \mathrm{kg}$ ) was administered in a 5-day regime with the first injection given immediately after hypoxic exposure. The damage of the ipsilateral hemisphere was evaluated by hematoxylin-eosin staining (HE) 6 days after the insult. Samples were collected at 24 and $48 \mathrm{~h}$ and 6 days. Effects of SB on hypoxia-ischemia (H)-induced inflammation (cytokines and chemokine) were assessed by Luminex assay and immunohistochemistry. Expression of molecular mediators (NFKB, p53, HSP70, COX-2, pro- and anti-apoptotic factors Bax, Bcl-2, caspase-3) were assayed by Western blot analysis.

Results: SB treatment-reduced brain damage, as assessed by HE staining, suppressed the production of inflammatory markers - IL-1 $\beta$, chemokine CXCL10, and blocked ischemia-elicited upregulation of COX-2 in the damaged ipsilateral hemisphere. Furthermore, administration of SB promoted the conversion of microglia phenotype from inflammatory M1 to anti-inflammatory M2. None of the investigated molecular mediators that are known to be affected by HDACis in adults were modified after SB administration.
\end{abstract}

Conclusions: Administration of SB is neuroprotective in neonatal hypoxia-ischemia injury. This neuroprotective activity prevented the delayed rise in chemokine CXCL10, IL-1 $\beta$, and COX-2 in the ipsilateral hemisphere. SB appears to exert a beneficial effect via suppression of HI-induced cerebral inflammation.

Keywords: Neonatal hypoxia-ischemia, Histone deacetylase inhibitors, Sodium butyrate, Neuroprotection, Microglia, Astrocytes, Cytokines, Inflammation

\footnotetext{
* Correspondence: terezal@imdik.pan.pl

${ }^{\dagger}$ Equal contributors

NeuroRepair Department, Mossakowski Medical Research Centre, Polish

Academy of Sciences, 5 A. Pawinskiego Street, 02-106 Warsaw, Poland
} 


\section{Background}

Histone deacetylase inhibitors (HDACis) are a heterogeneous group of agents that inhibit histone deacetylases (HDACs) and promote posttranslational acetylation of lysine residues within nuclear and cytoplasmic proteins, which may alter their activity and function. In particular, HDAC inhibition can have a profound effect on the acetylation status of histone proteins within chromatin, resulting in the augmented expression of genes relevant to protection from an ischemic insult. In addition, inhibition of deacetylation equally promotes the acetylation of non-histone proteins, such as transcription factors, signal transduction mediators, determining their interaction, localization, and stability [1]. It is very likely that the non-specificity of deacetylase inhibitors is responsible for the opposing effect noted in distinct type of cells. As it is becoming apparent, HDAC inhibition promotes the demise of tumor cells. The same drugs display strong protective properties for neurons in in vitro and in vivo models of neurotoxicity and neurodegeneration (for rev see [2]).

Furthermore, it was reported recently that the treatment of adult animals with histone deacetylase inhibitors, such as trichostatin A (TSA), sodium butyrate (SB), and vorinostat (SAHA), administered just before as well as after the onset of stroke, provides neuroprotection [3-8]. The neuroprotective effect of these agents has been associated with decreasing the lesion volume, neurobehavioral improvement, and stimulation of neurogenesis in the ischemic adult brain [9, 10]. Despite the growing number of evidence supporting the beneficial effect of HDACis in the experimental model of stroke in adult rodents, only a few available reports were addressed upon their effect in the hypoxia-ischemia (HI)-injured immature brain [11-13]. However, due to different experimental paradigms, it is not possible to make the explicit conclusion.

Neonatal HI encephalopathy still remains one of the most important causes of neonatal mortality and/or long-term neurological sequelae such as cerebral palsy, seizure disorders, cognitive and intellectual deficits, and behavioral problems [14-17]. Currently, there are no well-established treatments to reduce brain damage and it is still a big challenge to protect the newborns' brain from HI injury. The only available effective treatment, hypothermia, neither provides complete brain protection nor stimulates the repair necessary for neurodevelopmental outcome. Recently, HDACis are being considered as valuable tools to reduce or even to prevent HIinduced brain damage in neonates. Since many aspects of the evolving brain damage following the insult differ between adults and neonates, extrapolating data obtained in the mature brain to neonates is generally unwise. Therefore, the present study was undertaken to examine whether treatment with one of the HDACis, sodium butyrate $(\mathrm{SB})$, has neuroprotective effects in a rat model of neonatal HI. We aimed to assess whether SB action is associated with changes in molecular mediators that are crucial for inducing cerebral damage and thus be targeted for therapy. As inflammation is a wellrecognized pathogenic factor in perinatal brain injury, we analyzed the microglial and astrocytic cell response to SB treatment and the influence of SB on cytokines, transcription factors, HSP70, and pro- and anti-apoptotic proteins.

\section{Methods}

Experimental animal work was conducted according to regulations following European Union directives. Experimental procedures were approved by the Local Ethics Committee for Animal Experimentation. All efforts were made to minimize the number of animals and animal suffering in every step.

\section{Experimental neonatal hypoxia-ischemia}

Animals were housed under controlled temperature $\left(22{ }^{\circ} \mathrm{C} \pm 2\right)$, with a 12 -h light cycle period and pelleted food and water ad libitum. Cerebral hypoxia-ischemia was produced in 7-day-old (P7) Wistar rats of either sex by a permanent unilateral common carotid artery ligation, followed by systemic hypoxia $[18,19]$. As was previously reported, the ligation alone does not decrease cerebral perfusion below critical levels and the addition of hypoxia is required to cause brain infarct [20]. Briefly, pups were anesthetized with isoflurane (4\% induction, $2 \%$ maintenance) carried by $\mathrm{O}_{2}$. Once they were fully anesthetized, a midline neck incision was made and the left common carotid artery was exposed, double ligated with surgical silk, and cut between two ligatures. The incision was then sutured with monofilament nylon. Sham-operated animals underwent the same surgical procedure without the ligation of the carotid artery. The time length of anesthesia lasted on average $5 \mathrm{~min}$. After surgery, the rat pups were returned to their home cage for $1 \mathrm{~h}$ to recover. Later, the animals were placed for $1 \mathrm{~h}$ in a hypoxic chamber containing $7.6 \%$ oxygen balanced with nitrogen with controlled humidity and temperature maintained at $35{ }^{\circ} \mathrm{C}$.

The undamaged hypoxic hemisphere, as well as agematched sham-operated animals, served as controls. Pups from each litter were randomly assigned to four experimental groups (5 rats per group): (1) control group (vehicle treatment), (2) control animals (SB treatment), (3) animals which underwent HI (vehicle treatment), and (4) animals which underwent HI (SB treatment). Animals were sacrificed at specific time points $(12,24,48,72 \mathrm{~h}$ and 6 days) after the injury. 


\section{Drug administration}

Rats subjected to $\mathrm{HI}$ or sham operated were treated once a day with subcutaneous injections of sodium butyrate (SB; Sigma-Aldrich; $300 \mathrm{mg} / \mathrm{kg}$ body wt) [4] or vehicle (saline) starting immediately after hypoxic exposure and lasting up to 5 consecutive days.

\section{Tissue preparation}

Six days after $\mathrm{HI}$-anesthetized animals were perfused transcardially first with phosphate-buffered saline (PBS) followed by a fixative solution (4\% paraformaldehyde, PFA, in $0.1 \mathrm{M}$ phosphate buffer, $\mathrm{pH}$ 7.4). The brains were removed and submerged in the same fixative solution for $4 \mathrm{~h}$ at $4{ }^{\circ} \mathrm{C}$. Following postfixation brains were cryoprotected overnight in $30 \%$ sucrose solution (in $0.1 \mathrm{M} \mathrm{PBS}$ ), frozen rapidly using dry ice, and placed in $-80{ }^{\circ} \mathrm{C}$ storage.

For biochemical analysis, animals were sacrificed (12, $24,48,72 \mathrm{~h}$ and 6 days after $\mathrm{HI}$ ) through decapitation and the whole hemispheres were frozen on dry ice. All tissue samples were stored at $-80{ }^{\circ} \mathrm{C}$ until used.

\section{Brain injury evaluation}

Hematoxylin-eosin (HE) staining was performed to evaluate the neuroprotective effect of SB against ischemia-induced brain damage. Six days after the insult (at postnatal day 13), the pups were anesthetized with $100 \mathrm{mg} / \mathrm{kg}$ ketamine combined with $10 \mathrm{mg} / \mathrm{kg}$ xylazine and perfused. The brains were dissected and frozen on dry ice. Coronal cryostat sections $(20 \mu \mathrm{m})$ were stained with $\mathrm{HE}$ and examined using light microscopy.

\section{Immunohistochemistry}

The following antibodies (source and final dilution) were used for tissue staining: mouse monoclonal anti-ED1 (CD68) (AbD Serotec, 1:100), goat polyclonal anti-Arg-1 (arginase-1) (Santa Cruz, 1:250), rabbit polyclonal antiIL-1 $\beta$ (Santa Cruz, 1:250), rabbit polyclonal anti-GFAP (Glial Fibrillary Acidic Protein, DAKO, 1:200), and chicken polyclonal anti-GFAP (Millipore, 1:200).

Coronal cryostat sections of the brain $(30 \mu \mathrm{m}$ thick) were cut at the level of the lateral ventricles in serial order to create 10 series sections. Double fluorescent immunohistochemistry was performed on free-floating sections. After blocking for unspecific reactivity, adjacent series of sections were stained for a specific cell-lineage marker.

For identification of the type of microglia, we used markers labeling M1 (ED1/IL-1 $\beta$ ) and M2 (ED1/arginase-1) cells. Double labeling was also employed for monitoring astrocytes expressing IL-1 $\beta$. Tissue sections were rinsed in PBS and then incubated in $10 \%$ normal goat serum in PBS containing $0.25 \%$ Triton X-100 for $60 \mathrm{~min}$ in room temperature (RT). Next, the sections were washed with PBS and incubated with anti-ED-1 or
anti-GFAP overnight at $4{ }^{\circ} \mathrm{C}$. The following day, tissue sections underwent the washing procedure, and the primary antibodies were revealed by applying appropriate secondary FITC-conjugated antibodies (AlexaFluor, 1:500) for $60 \mathrm{~min}$ at room temperature and in the dark. After this step, the sections were rinsed in PBS and incubated with primary antibodies (anti-Arg-1 or anti-IL$1 \beta$ ) overnight at $4{ }^{\circ} \mathrm{C}$. The next day, after being rinsed in $\mathrm{PBS}$, the sections were exposed to appropriate $\mathrm{Cy3}$ conjugated secondary antibodies (AlexaFluor, 1:500) for $1 \mathrm{~h}$ at room temperature. Nuclei were subsequently labeled with the fluorescent dye Hoechst $33258(2 \mu \mathrm{g} / \mathrm{ml}$ PBS; Sigma).

Labeling was verified using a confocal laser scanning microscope (LSM 780, Carl Zeiss, Germany) using a 10× or $20 \times$ objective. A helium-neon laser $(543 \mathrm{~nm})$ was utilized in the excitation of Alexa Fluor 546, while an argon laser $(488 \mathrm{~nm})$ was applied in the excitation of FITC. Image software was used for quantitative analysis of immunoreactive sections. Five animals per group were analyzed. Images from five sections per animal were taken, and the number of positive-labeled cells as well as fluorescence intensity was assessed in an area of $1.44 \mathrm{~mm}^{2}$.

\section{Determination of cytokine expression in brain extracts}

Concentrations of chemokines/cytokines were measured in extracts from brain hemispheres using the EMD Millipore's MILLIPLEX ${ }^{\bullet}$ MAP Rat Cytokine/ Chemokine Magnetic Bead assay according to the manufacturer's instructions. The cytokines and chemokines analyzed included TNF $\alpha$, IL-1 $\alpha$, IL-1 $\beta$, IL-2, IL-4, IL-6, IL-12, IFN- $\gamma$, and chemokine CXCL10 (IP-10). The median fluorescence intensity plates were assayed on a Bio-Plex ${ }^{\circ}$ 200 Luminex system with Bio-Plex Manager 5.0 software. The five-parameter logistic method was applied to estimate cytokine/chemokine concentrations in brain homogenates.

\section{Quantitative polymerase chain reaction (real-time PCR)}

Gene expression of pro-inflammatory (TNF $\alpha$, IL-1 $\beta$ ) cytokines was evaluated in the brain hemispheres obtained from rats 12,48 and $72 \mathrm{~h}$ after HI. Total RNA was isolated with TRIzol Reagent, and the quality and concentration of RNA was verified by spectrophotometry with the Nanodrop ${ }^{\text {Tax }}$ apparatus. The samples containing $1 \mu \mathrm{g}$ of total RNA were reverse transcripted using High Capacity RNA-to-cDNA Kit (Applied Biosystems) according to the manufacturer's instructions.

Quantitative real-time PCR analyses of cDNA samples (300 ng) with designed specific primers (Table 1) and Fast SYBR Green Master Mix (Applied Biosystems) were performed in 7500 Fast Real-Time PCR System (Applied Biosystem). Reaction parameters were as follows: (1) holding stage, $20 \mathrm{~s}$ at $95{ }^{\circ} \mathrm{C}$; (2) cycling stage $(40 \times)$, $3 \mathrm{~s}$ 
Table 1 List of designed primers used in reverse transcription and quantitative real-time (RT)-PCR analysis

\begin{tabular}{|c|c|c|}
\hline Gene & Forward primer sequence & Reverse primer sequence \\
\hline$\overline{I L-1 \beta}$ & 5'-CACCTCTCAAGCAGAGCACAG-3' & 5'-GGGTTGCATGGTGAAGTCAAC-3' \\
\hline TNFa & 5'-AAATGGGCTCCCTCTCATCAGTCC-3' & 5'-TCTGCTTGGTGGTITGCTACGAC-3' \\
\hline SDHA & 5'-CCCTGAGCATTGCAGAATC-3' & 5'-CATTTGCCTTAATCGGAGGA-3' \\
\hline
\end{tabular}

at $95{ }^{\circ} \mathrm{C}$ and $30 \mathrm{~s}$ at $60{ }^{\circ} \mathrm{C}$; and (3) melt curve stage, $15 \mathrm{~s}$ at $95{ }^{\circ} \mathrm{C}, 1 \mathrm{~min}$ at $60{ }^{\circ} \mathrm{C}, 15 \mathrm{~s}$ at $95^{\circ} \mathrm{C}$, and $15 \mathrm{~s}$ at $60{ }^{\circ} \mathrm{C}$. Each sample was tested in triplicate during two analyzing sessions. The fluorescence signal from specific transcript was normalized against that of reference gene (SDHA), and threshold cycle values $(\Delta \mathrm{Ct})$ were quantified as fold changes by the $2^{-\Delta \Delta C T}$ method.

\section{Western blot analysis}

The following antibodies (source and final dilution) were used for analysis: mouse monoclonal anti-NFkB (Cell Signaling, 1:1000), rabbit polyclonal anti-p53 (Cell Signaling, 1:1000), rabbit polyclonal anti-HSP70 (Cell Signaling, 1:1000), rabbit monoclonal anti-COX-2 (Cell Signaling, 1:1000), rabbit polyclonal anti-Bcl-2 (Cell Signaling, 1:1000), rabbit polyclonal anti-Bax (Cell Signaling, 1:1000), and mouse monoclonal anti-actin (MP Biomedicals, 1:500).

Brain tissues were homogenized in RIPA lysis buffer (10 mM Tris- $\mathrm{HCl} \mathrm{pH} 7.5$ containing $150 \mathrm{mM} \mathrm{NaCl}, 1 \%$ Nonidet P40, 0.1\% SDS, 1\% Triton X-100, PMSF $0.1 \mathrm{mg} /$ $\mathrm{ml}$ ) and a proteinase and phosphatase inhibitor cocktail (Life Technologies, 1:100). Lysates were clarified by centrifugation at $13000 \mathrm{~g}$ for $10 \mathrm{~min}$ at $4{ }^{\circ} \mathrm{C}$. The supernatant was collected, and protein concentrations were determined using a Bio-Rad DCTM protein assay kit (Bio-Rad). Samples (50 $\mu$ g protein) were ran on $10-15 \%$ SDS-PAGE gels and transferred onto nitrocellulose membranes (Amersham Bioscience). After blocking, membranes were probed with specific primary antibodies and then incubated with horseradish peroxidaseconjugated secondary IgG antibodies (Sigma-Aldrich). Immunoblot signals were visualized using ECL chemiluminescence kit (GE Healthcare Life Sciences). To verify an equal loading of protein per line, the $\beta$-actin antibody was used as an internal control for each immunoblotting. Semi-quantitative evaluation of protein levels detected by immunoblotting was performed by computer-assisted densitometric scanning (LKB Utrascan XL, Program GelScan). The level of protein immunoreactivity was determined by frequent analysis of multiple immunoblots.

\section{Quantitative measurement of prostaglandin E2 protein concentration}

To estimate the amount of prostaglandin E2 (PGE2) in homogenates obtained from the brain hemispheres, the Prostaglandin E2 ELISA Kit-Monoclonal (Cayman) test was applied according to the supplier's instructions. Frozen hemispheres were homogenized in $1 \mathrm{ml}$ of $0.1 \mathrm{M}$ phosphate buffer ( $\mathrm{pH} 7.4$ ) containing $1 \mathrm{mM}$ EDTA and $10 \mu \mathrm{M}$ indomethacin. Homogenates were clarified by centrifugation at $8000 \mathrm{~g}$ for $10 \mathrm{~min}$ at $4{ }^{\circ} \mathrm{C}$, and the supernatant was collected for analysis. Protein concentrations were determined using a Bio-Rad DC ${ }^{\text {тм }}$ protein assay kit (Bio-Rad). After performing the Sandwich ELISA assay, the plates were read at $412 \mathrm{~nm}$ using a spectrophotometric plate reader Fluorostar Omega (BMG LabTech).

\section{Quantitative measurement of caspase-3 activity}

To estimate the level of activated caspase- 3 in lysates obtained from both brain hemispheres, the Caspase-3 Fluorescence Assay Kit (Cayman Chemical) was applied according to the supplier's instructions. Briefly, the kit employs a specific caspase-3 substrate, N-Ac-DEVDN'-MC-R110, which, upon cleavage by active caspase-3, generates a highly fluorescent product that is easily quantified. The fluorescence intensity of each was well read using a spectrophotometric plate reader Fluorostar Omega (BMG LabTech; excitation $=485 \mathrm{~nm}$, emission $=535 \mathrm{~nm})$.

\section{Statistical analysis}

GraphPad PRISM 5.0 software was used for the statistical analysis of the received data. Comparisons between animal groups were performed using the one-way analysis of variance (ANOVA) followed by the Bonferroni post-hoc test for multiple comparisons or Student's $t$ test. All values are expressed as mean $\pm \mathrm{SD}$. The data were considered significant at $p$ value $<0.05$.

\section{Results}

Sodium butyrate reduces brain damage after neonatal $\mathrm{HI}$ Both the left and right brain hemispheres of all rats (sham control, HI with or without SB treatment) were subjected to histological evaluation at 6 days after the insult (P13). Coronal sections (cut at the level of the lateral ventricles) stained with $\mathrm{HE}$ show the loss of neurons and signs of cerebral edema with swollen cells throughout the ipsilateral frontal cortex exclusively (Fig. 1). Administration of SB immediately after HI provided almost complete neuroprotection in comparison with nontreated animals. Neither neuronal loss nor edema was 


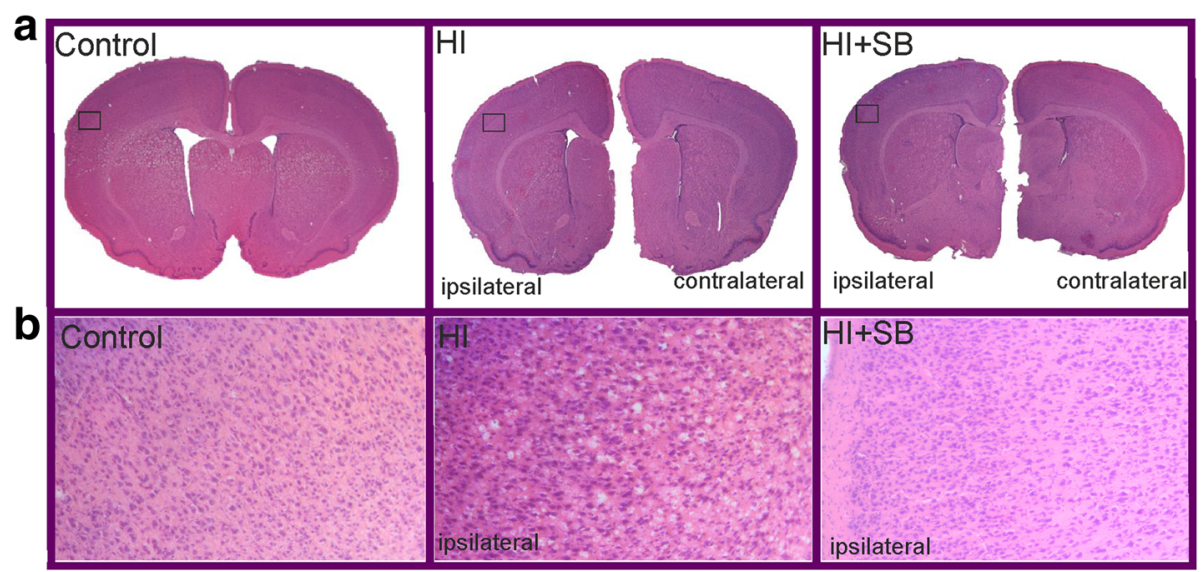

Fig. 1 Sodium butyrate treatment reduces hypoxia-ischemia- induced brain damage in neonates. Seven-day-old rats (PND7) were subjected to hypoxia-ischemia followed by 6 days of recovery. SB or vehicle was administered directly after the onset of HI and for 5 consecutive days. a Brain coronal sections from sham control animals and from animals 6 days after hypoxia-ischemia (with or without SB treatment) were stained with hematoxylin-eosin (HE). b Lower panel represents magnification (100x) of the ipsilateral hemisphere area (marked with rectangles in a). Note the loss of neurons and signs of cerebral edema in the cortex of ipsilateral hemisphere. Sodium butyrate administration provided almost complete neuroprotection in comparison with non-treated animals. Photomicrographs are representative of observations made from five animals per group

observed. Furthermore, the brain slices demonstrated proper cytoarchitecture.

\section{SB-modified microglial/macrophage and astroglial response to neonatal $\mathrm{HI}$ \\ Microglia}

To determine the effect of SB administration on cerebral activation/influx of microglia/macrophages after hypoxiaischemia, we performed ED1 staining on the brain sections of sham-operated, $\mathrm{HI}$, and $\mathrm{HI}+\mathrm{SB}$ rat pups. The data presented in Fig. 2 shows numerous ED1-positive cells in ipsilateral hemisphere at 6 days after HI. Most microglial cells were round shaped with thick processes and were considered to be in an activated state. The activated microglial cells were scattered throughout the entire cortex and striatum. Contrary, in slices obtained from control animals, as well as from contralateral hemispheres, the activated microglial cells were not detected $(p<0.001$, ipsi vs. contra). Sodium butyrate administration resulted in an increased number of microglial cells to $150 \%$ of vehicle-treated animals in the ipsilateral side.

Next, we examined whether SB promotes the polarization of microglia from M1- to M2-like phenotype after HI. To address this, we performed double staining with IL-1 $\beta$ antibody coupled with ED1 for the identification of activated proinflammatory M1 phenotype and ED1/arginase-1 for anti-inflammatory M2-like phenotype (Fig. 3a, b). Six days after $\mathrm{HI}$, the majority of ED1-positive cells expressed IL-1 $\beta$ in the cortical region of the ipsilateral hemisphere, with only a few cells stained positively with ED1/Arg-1. The administration of SB after HI led to a marked decrease in the amount of cells presenting the M1 phenotype of microglia (HI vs $\mathrm{HI}+\mathrm{SB}, p<0.001)$ with concomitant enhancement of cells stained with ED1/Arg-1 specific for M2 type (HI vs $\mathrm{HI}+\mathrm{SB}, p<0.001)$.

\section{Astrocytes}

Figure 4 shows that 6 days after neonatal HI, the GFAPassociated fluorescent signal increased in the ipsilateral hemisphere; however, this elevation was not statistically significant compared to the contralateral side. Astrocytes presented an activated phenotype characterized by hypertrophic processes. SB treatment resulted in an over twofold elevation in the GFAP staining intensity in the ipsilateral hemisphere. In addition, the hypertrophy of astrocytic cells was more pronounced and associated with inter-digitations of processes that overlapped and formed glial scars.

We also determined the effect of SB treatment after $\mathrm{HI}$ on the number of GFAP-positive cells co-stained with cytokine IL-1 $\beta$ antibody (Fig. 5a, b). Our results show that 6 days following HI, a majority of astroglial cells express IL- $1 \beta$ within the cortex of the damaged ipsilateral hemisphere. The amount of these cells was markedly reduced upon SB administration (HI vs $\mathrm{HI}+\mathrm{SB}, p<0.001$ ).

\section{Effect of SB on inflammatory markers Effect of SB on cytokines}

Cytokines IL-1 $\alpha$, IL-1 $\beta$, IL-2, IL-4, IL-6, IL-12, chemokine CXCL-10, tumor necrosis factor alpha (TNF $\alpha)$, and interferon-gamma (IFN- $\gamma$ ) were measured, and differences between ipsilateral (hypoxic-ischemic) vs contralateral (hypoxic) hemispheres, as well as vs sham control, were compared at $48 \mathrm{~h}$ and 6 days after the injury in animals treated with vehicle or SB. 

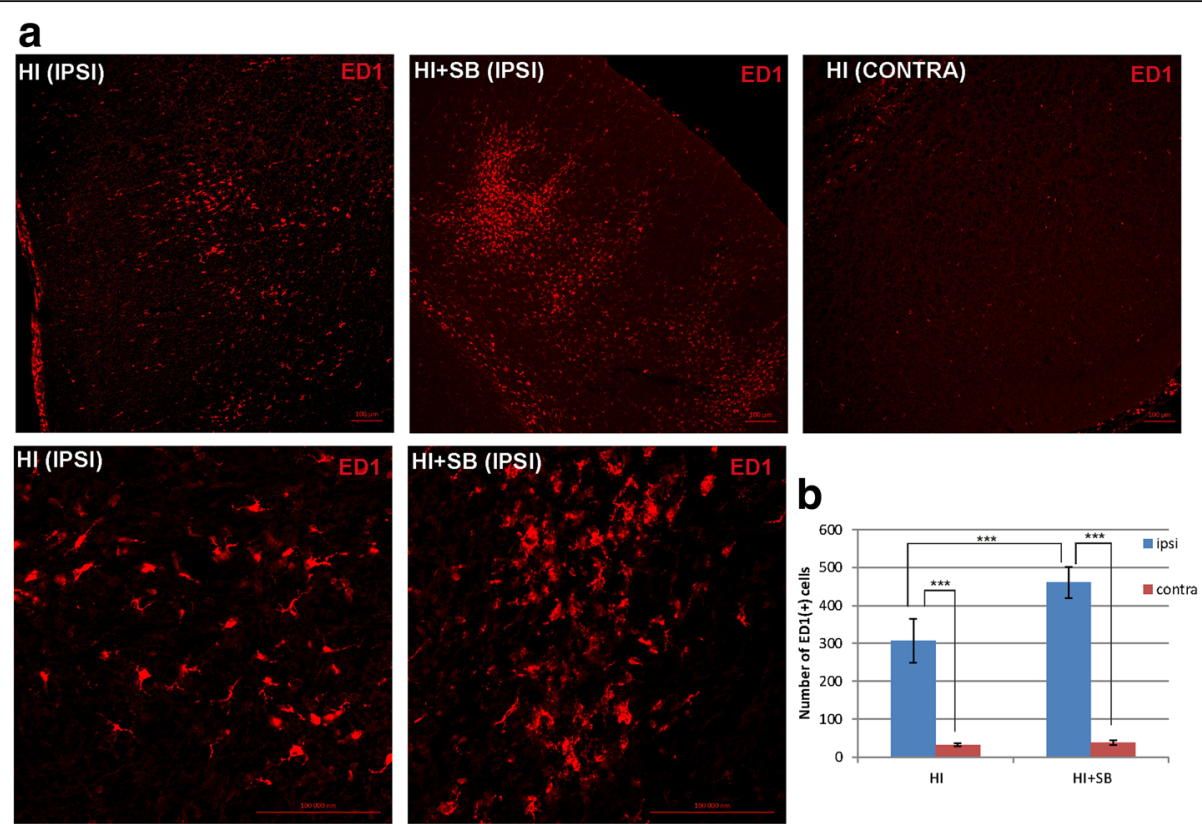

Fig. 2 Sodium butyrate increases microglial/macrophage cell number in the ipsilateral hemisphere after neonatal hypoxia-ischemia. Seven-dayold rats (PND7) were subjected to hypoxia-ischemia followed by 6 days of recovery. SB or vehicle was administered directly after the onset of HI and for 5 consecutive days. Brain sections were stained for ED1 immunoreactivity (red). a Confocal photomicrographs show immunohistochemical reaction in the frontal cortex of ipsilateral (injured) and contralateral (control) hemispheres with or without SB treatment. Numerous ED1-positive cells are mainly seen in ipsilateral side, and their number further increases after SB administration. Lower panel represents magnification of the upper ipsilateral photomicrographs. Scale bar $100 \mu \mathrm{m}$. b Graph shows the number of ED1-labeled cells quantified in the frontal cortex (1.44 mm² area). The values represent means \pm SD of five animals per each experimental group. The one-way ANOVA and Bonferroni test indicate significant differences in the number of ED1(+) cells between the investigated groups: ${ }^{* *} p<0.001$. IPS/ ipsilateral hemisphere, CONTRA contralateral hemisphere

We found a large individual variation in the cytokine levels after $\mathrm{HI}$, and not all of them present elevated levels after HI (Fig. 6). A significantly increased amount of proinflammatory IL- $1 \alpha$, IL- $1 \beta$, TNF $\alpha$, and chemokine CXCL10 (IP-10) was observed in the ipsilateral hemisphere at $48 \mathrm{~h}$ compared to the control one. However, the degree of significance in the case of TNF $\alpha$ and IL- $1 \alpha$ reached $p<0.05$, for IL- $1 \beta p<0.01$, and for the chemokine $p<0.0001$. It is worth to note that the concentration of IL-1 $\beta$ and chemokine remained elevated up to 6 days of survival time $(p<0.01$ and $p<0.05$, respectively, HI vs sham control). In contrast, in the contralateral hemisphere, the level of these molecules did not differ from the controls. SB significantly suppressed upregulation of the CXCL10 chemokine at $48 \mathrm{~h}$ post$\mathrm{HI}(p<0.001$, HI vs $\mathrm{HI}+\mathrm{SB})$. The reduction of IL- $1 \beta$ in the $\mathrm{HI}$ hemisphere occurred later, at 6 days of recovery $(p<0.05, \mathrm{HI}$ vs $\mathrm{HI}+\mathrm{SB})$. In the case of TNF $\alpha$ and IL$1 \alpha$, the SB action was expressed only by the tendency to lessen the concentration of this protein.

No notable differences between hemispheres were observed in IL-2, IL-6, IL-12, IFN $\gamma$, and anti-inflammatory IL- 4 at $48 \mathrm{~h}$ and 6 days post-HI. The expression pattern of these molecules did not change after SB administration (data not shown).
To investigate if the pattern of protein concentration changes of IL-1 $\beta$ and TNF $\alpha$ (Fig. 7) is similar to that presented by the expression of their messenger RNA (mRNA), we performed qRT-PCR at different time points following HI. As shown in Fig. 7, HI insult led to a remarkable increase in IL-1 $\beta(p<0.05)$ and TNF $\alpha$ $(p<0.01)$ mRNA level by more than three- and fourfold, respectively, in the ipsilateral hemisphere $12 \mathrm{~h}$ after $\mathrm{HI}$, when compared with the matching controls. A significantly elevated level for TNF $\alpha$ mRNA also remained $48 \mathrm{~h}$ after $\mathrm{HI}(p<0.01)$, but was reduced to the control level in the presence of $\mathrm{SB}(\mathrm{HI}$ vs $\mathrm{HI}+\mathrm{SB}$, $p<0.01)$. This was the only action manifested by the histone deacetylase inhibitor. At a later time point, the level of both cytokines decreased and no considerable changes in gene expression were noticed at $72 \mathrm{~h}$ post$\mathrm{HI}$, regardless of animal groups.

\section{Effect of SB on COX-2}

COX-2 is the rate-limiting enzyme for prostanoid synthesis and an inflammatory marker. The COX-2 protein expression was determined by Western blotting and scanning densitometry (Fig. 8 a, b). At 24 h after HI, we observed only an increasing, however not significant tendency in the hypoxic-ischemic hemisphere. The robust 


\section{a}
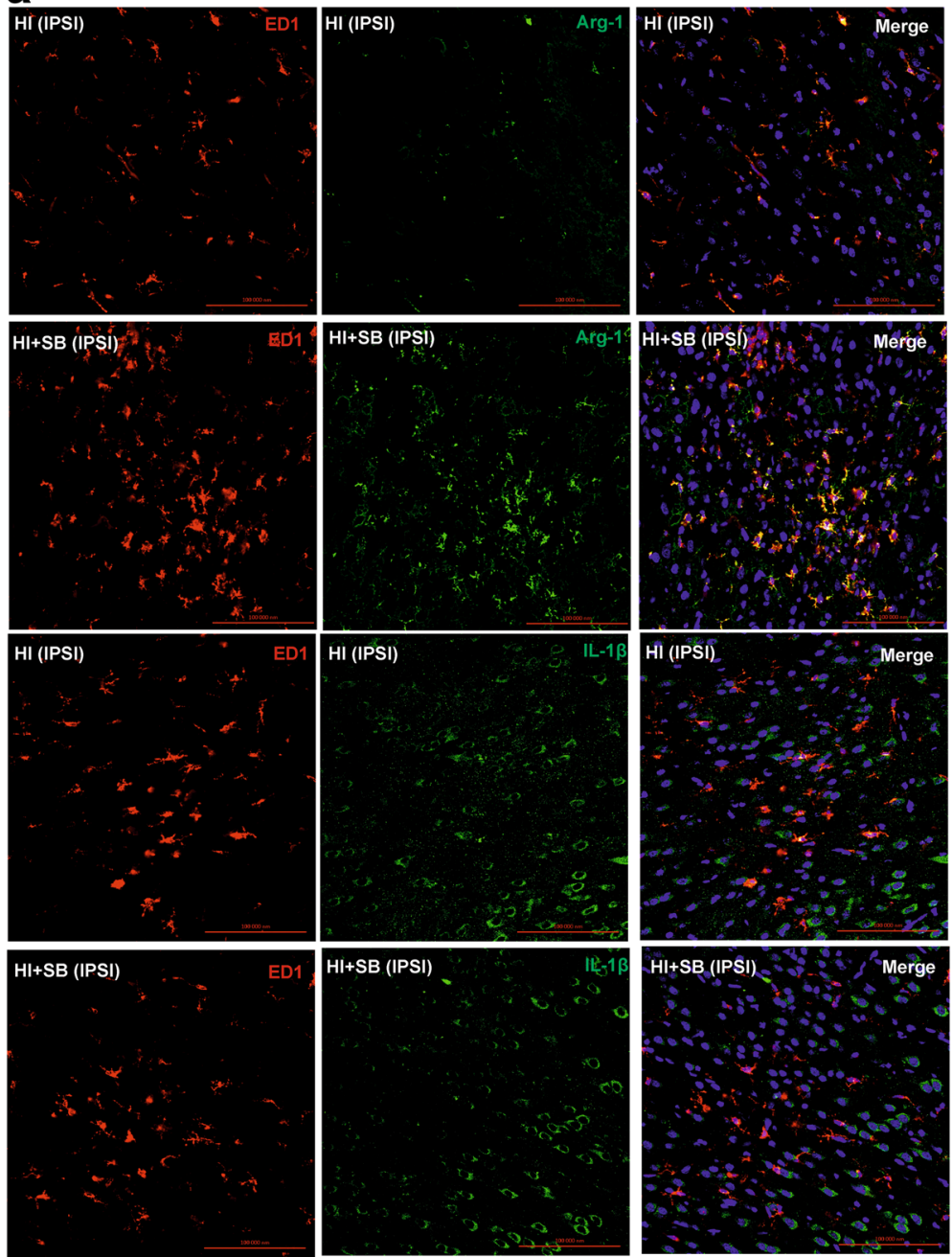

b
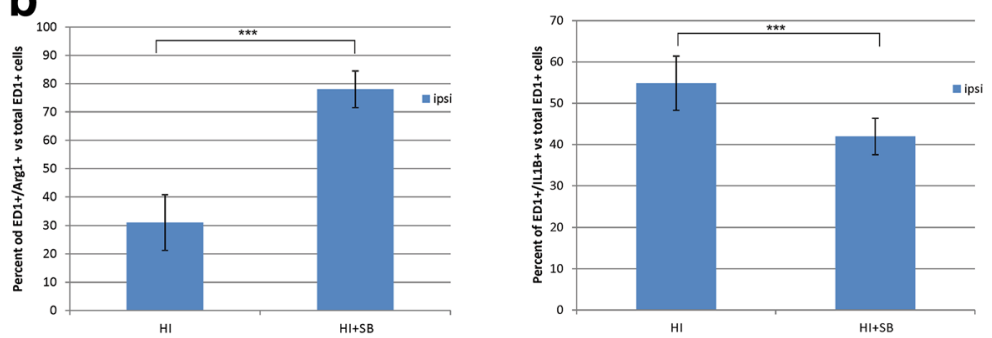

Fig. 3 Sodium butyrate promotes the polarization of microglia from M1- to M2-like phenotype after neonatal hypoxia-ischemia. Seven-day-old rats (PND7) were subjected to hypoxia-ischemia followed by 6 days of recovery. SB or vehicle was administered directly after the onset of $\mathrm{HI}$ and for 5 consecutive days. Sections from ipsilateral hemispheres were stained for ED1 immunoreactivity (red), for arginase-1 (Arg-1), marker specific for M2 phenotype (green), and for IL-1 3 , marker for M1 phenotype (green). Nuclei were labeled with the Hoechst dye (blue). Six days after HI, the majority of ED1-positive cells expressed IL-1 3 , with only a few cells co-stained with ED1/Arg-1. The administration of SB after HI led to a marked decrease in the amount of cells presenting the M1 (ED1/IL-1 $\beta$ positive) phenotype of microglia with concomitant enhancement of cells stained with ED1/Arg-1 specific for M2 type. a Photomicrographs are representative of observations made from 5 animals per experimental group. Scale bar $100 \mu \mathrm{m}$. $\mathbf{b}$ Graphs show the percent of the ED1(+)/Arg-1(+) and ED1(+)/IL-1 $\beta$ (+) cells versus total pool of ED1-positive cells quantified in the frontal cortex (1.44 $\mathrm{mm}^{2}$ area). The values represent means \pm SD of five animals per each experimental group. Student's $t$ test indicates significant differences in the number of ED1(+)/Arg-1(+) and ED1(+)/IL-1 $\beta(+)$ cells between the investigated groups: ${ }^{* *} p<0.001$. IPS/ ipsilateral 

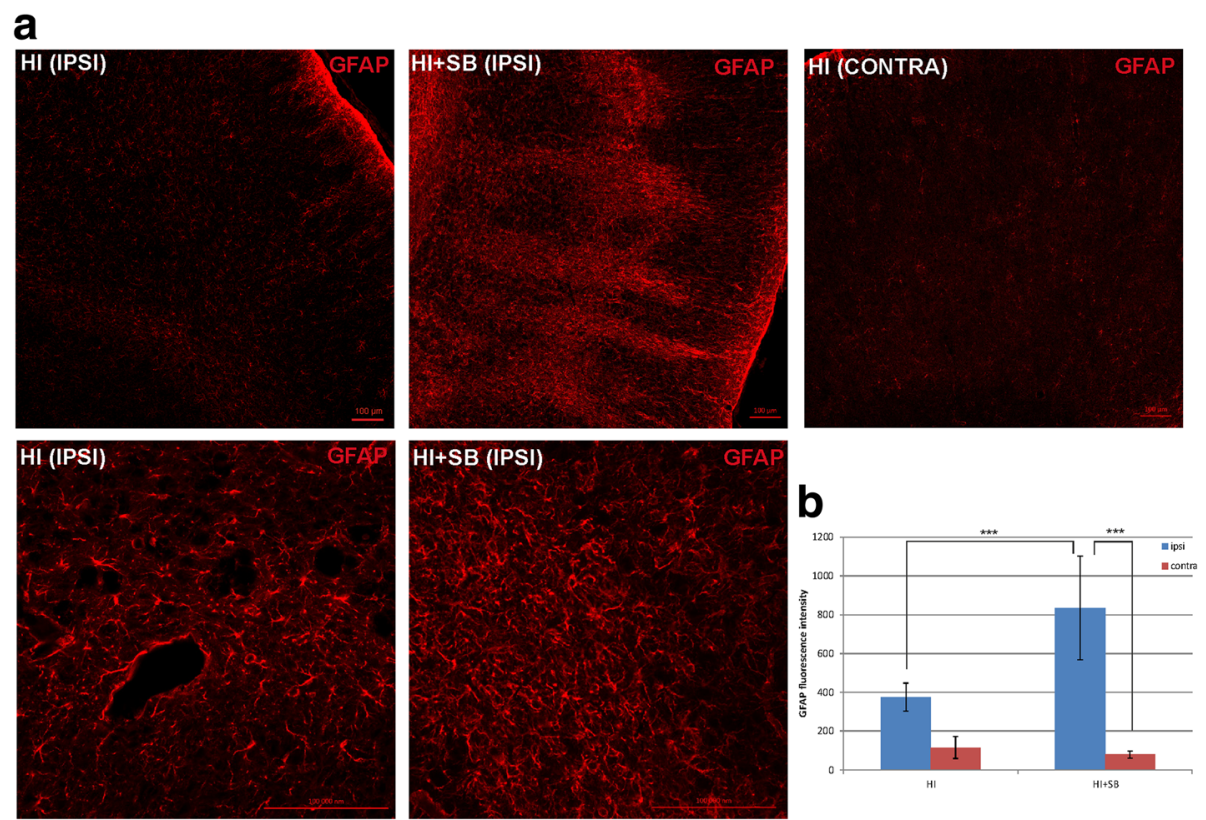

Fig. 4 Sodium butyrate increased the amount of reactive astrocytes in the rat ipsilateral hemisphere after neonatal hypoxia-ischemia. Seven-day-old rats (PND7) were subjected to hypoxia-ischemia followed by 6 days of recovery. SB or vehicle was administered directly after the onset of HI and for 5 consecutive days. Brain sections were stained for GFAP immunoreactivity (red). a Confocal photomicrographs show immunohistochemical reaction in the frontal cortex of contralateral (control) and ipsilateral (injured) hemispheres with or without SB treatment. Note the increased amount of GFAP-positive cells in injured side 6 days after hypoxia-ischemia. SB administration resulted in a significant elevation in the GFAP staining intensity in the ipsilateral hemisphere in comparison to vehicle-treated animals. Lower panel represents magnification of the upper photomicrographs. Scale bar $100 \mu \mathrm{m}$. b Graph shows the GFAP-associated fluorescent signal quantified in the frontal cortex (1.44 $\mathrm{mm}^{2}$ area). The values represent means \pm SD of five animals per experimental group. The one-way ANOVA and Bonferroni test indicate significant differences in GFAP fluorescence intensity between the investigated groups: ${ }^{* *} p<0.001$. IPS/ ipsilateral, CONTRA contralateral

HI-induced elevation of COX-2 protein expression in the ipsilateral hemisphere by about threefolds compared to that of sham control $(p<0.01)$ was seen at 6 days after the insult. Administration of SB reduced the immunoreactivity level to the value presented by the respective sham $(p<0.01$, HI vs HI $+\mathrm{SB})$.

\section{Effect of $S B$ on prostaglandin $E_{2}$}

As shown on Fig. 9, the concentration of PGE2 at 24 h after HI markedly increased when compared to control $(p<0.05)$. The administration of SB had no noticeable impact. Furthermore, the pattern of PGE2 changes remains close to that presented by COX2. The elevation of COX-2 protein concentration in the ipsilateral hemisphere seen at 6 days after HI remains in agreement with increased PGE2 $(p<0.001)$. However, despite that treatment with SB induced a decrease in COX-2 expression at this time point, it does not influence the concentration of PGE2 which remains on a high level.

\section{SB treatment modified expression of transcription factors (NFKB, p53) and HSP70}

Subsequently, we checked if SB counteracts the action of chosen transcription factors: NFkB and p53, and HSP70.

\section{$N F K B$}

As depicted on Fig. 8 c, d, exposure of 7-day pups to HI caused significant elevation of $\mathrm{NF} \mathrm{B}$, almost equally in the both brain hemispheres (ipsi- and contralateral), compared to the sham control (about 1.5-fold; $p<0.01$ ) at $24 \mathrm{~h}$ of recovery. As a result of SB treatment, the level of protein returned to the control level and this was the only noticeable effect of the histone deacetylase inhibitor action. At the later time points after the injury, the level of NFKB had the tendency to increase; however, densitometric analysis of the respective blots did not indicate any significant changes between experimental groups.

\section{p53}

The level of p53, the apoptosis regulating transcription factor, was estimated at 24 and $48 \mathrm{~h}$ of recovery after HI. As shown in Fig. 8 e, f, the insult did not alter significantly the immunoreactivity level; however, the trend was noticed towards higher expression of p53 in the hypoxic-ischemic hemisphere, compared with the hypoxic only, contralateral side, as well as with sham control. Importantly, administration of SB after the onset of $\mathrm{HI}$ in any case did not suppress the expression level of p53. 

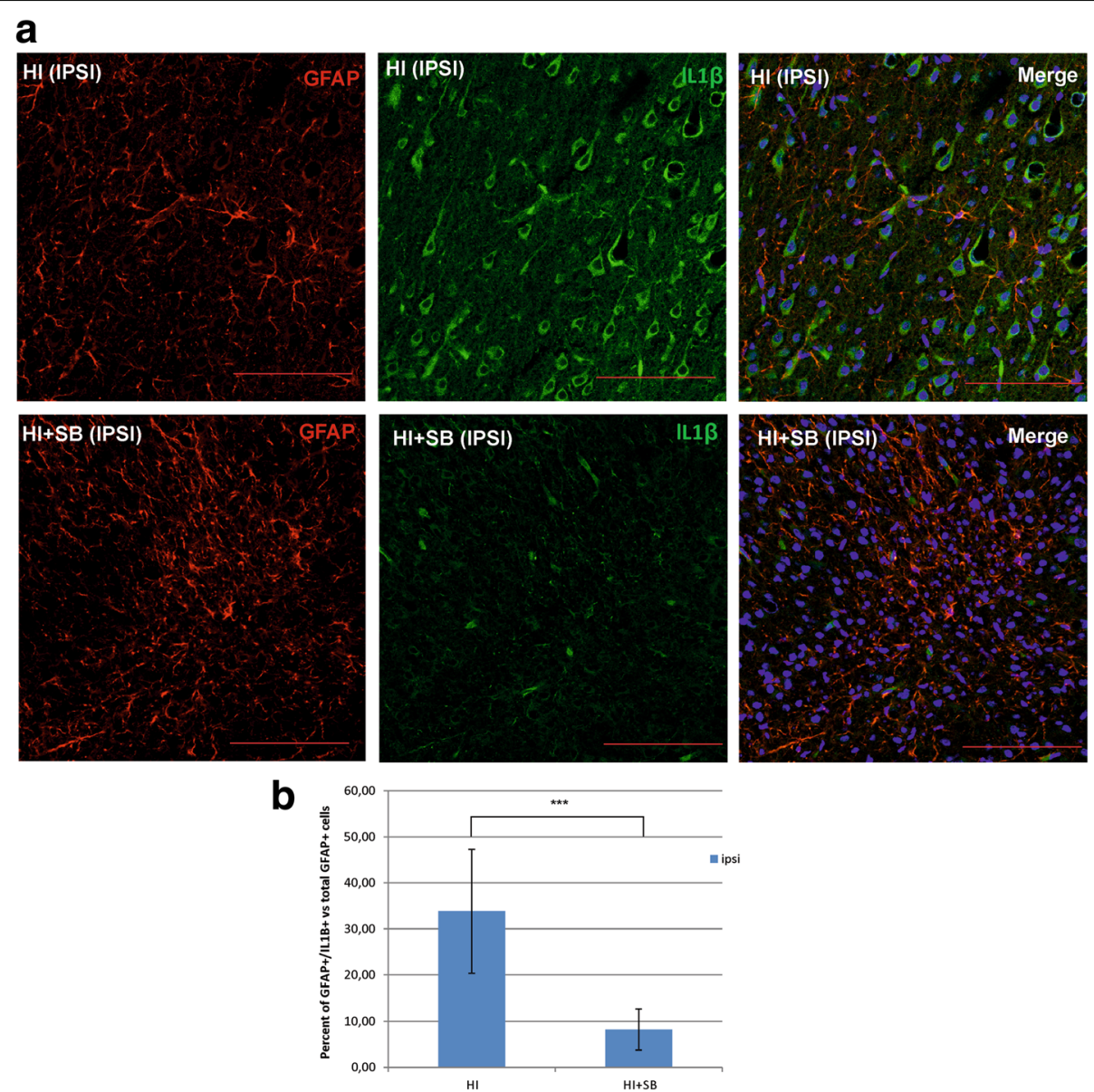

Fig. 5 Sodium butyrate decreases IL-1 $\beta$ expression in astrocytes. Seven-day-old rats (PND7) were subjected to hypoxia-ischemia followed by 6 days of recovery. SB or vehicle was administered directly after the onset of $\mathrm{HI}$ and for 5 consecutive days. Brain sections from ipsilateral hemispheres were stained for GFAP immunoreactivity (red) and for IL-1 $\beta$ (green). Nuclei were labeled with the Hoechst dye (blue). The majority of astroglial cells expressed IL-1 $\beta$ within the cortex of ipsilateral side. The amount of these cells was markedly reduced after SB administration. a Photomicrographs are representative of observations made from 5 animals per experimental group. Scale bar $100 \mu \mathrm{m}$. $\mathbf{b}$ Graph shows the percent of the GFAP(+)/IL-1ß (+) cells versus total pool of GFAP-positive cells quantified in the frontal cortex $\left(1.44 \mathrm{~mm}^{2}\right.$ area). The values represent means \pm SD of five animals per each experimental group. Student's $t$ test indicates significant differences in the number of GFAP(+)/IL-1 $\beta(+)$ cells between the investigated groups: ${ }^{* * *} p<0.001$. IPS/ ipsilateral

\section{HSP70}

According to generally accepted data indicating the correlation between HSP induction and resistance to brain damage, we aimed to evaluate the role of HSP70 as a potential mediator of the neuroprotective effects of exogenously administered SB. Figure 8 g, h shows representative immunoblots and relative intensity of changes (quantified by scanning densitometry). The data revealed that $24 \mathrm{~h}$ after $\mathrm{HI}$, the immunoreactivity of HSP70 declined in the ipsilateral side to $80 \%$ of control values $(p<0.01$, control vs $\mathrm{HI})$. We did not observe any change in HSP70 expression in this time point in the contralateral hypoxic hemisphere of HI-treated rats. Unexpectedly, the administration of SB led to a further decrease of HSP70 expression (to $69 \%$ of control; $p<0.001$ ). An increased expression of HSP70 after SB injection was found in both brain hemispheres, compared to respective vehicle-treated animals, at 6 days of recovery $(p<$ 0.05 , vehicle treated vs SB treated).

\section{Effect of SB on pro- and anti-apoptotic proteins}

To address the question whether the neuroprotective action of SB is associated with an influence on apoptosis related factors, we assayed the levels of activated caspase-3, Bax, and Bcl-2.

\section{Caspase 3}

Activity of caspase-3 is expressed by the level of fluorescence generated upon cleavage of specific caspase-3 substrate (N-Ac-DEVD-N'-R110). As shown in the graph (Fig. 10), HI induced a significant increase in caspase-3 activity in the ipsilateral hemisphere noticed at 24 and 

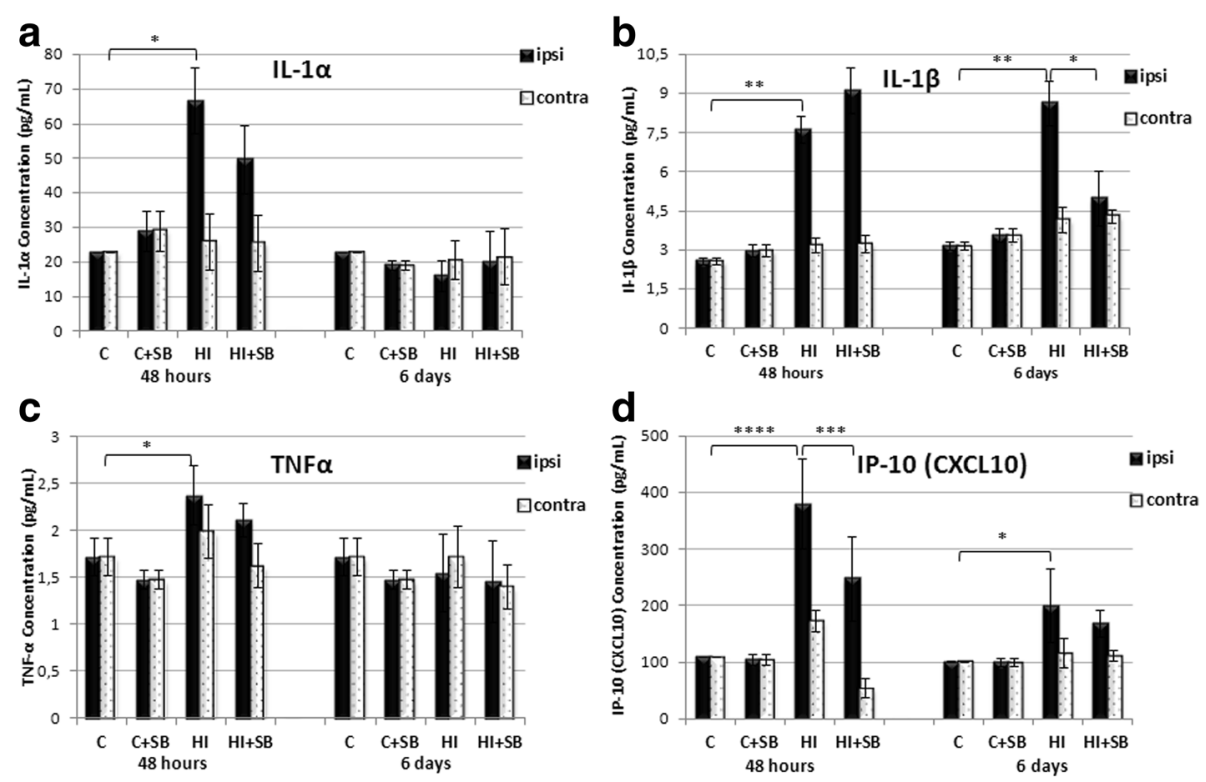

Fig. 6 Effects of SB treatment on the level of cytokines/chemokines in the brain after neonatal HI. Seven-day-old rats (PND7) were subjected to hypoxia-ischemia followed by $48 \mathrm{~h}$ or 6 days of recovery. SB or vehicle was administered directly after the onset of $\mathrm{HI}$ and for 2 or 5 consecutive days (determined by the experimental paradigm). The concentrations of proinflammatory cytokines (pg/ml): IL-1a (a), IL-1 $\beta$ (b), TNFa (c), and chemokine IP-10 (CXCL10) (d) were determined in the ipsilateral (injured) and contralateral hemispheres. Bar graphs represent statistical analysis of the data from indicated experimental groups: vehicle control (C), SB-treated control (C + SB), vehicle-treated hypoxia-ischemia (HI), and SB-treated hypoxia-ischemia $(\mathrm{HI}+\mathrm{SB})$. Note the suppression of HI-induced upregulation of IP-10 and IL-1 $\mathrm{B}$ at $48 \mathrm{~h}$ and 6 days of recovery, respectively, after SB treatment. The values represent means \pm SD from five animals in each group. The one-way ANOVA and Bonferroni test: ${ }^{*} p<0.05,{ }^{* *} p<0.01,{ }^{* * *} p<0.001$, and ${ }^{* * * *} p<0.0001$. C control, ipsi ipsilateral, contra contralateral

$48 \mathrm{~h}$ of recovery, compared to sham control $(p<0.0001$ and $p<0.05$, respectively). Only a tendency to increase the activity of caspase- 3 was simultaneously observed within the contralateral hypoxic hemisphere at $24 \mathrm{~h}$ after the insult. There was no effect of HDACi on the activity of caspase- 3 in the injured ipsilateral side.

\section{The assay of Bax and $\mathrm{BCl}-2$}

The levels of pro- and anti-apoptotic proteins Bax and Bcl-2, respectively, were evaluated by Western immunoblotting analyses. Figure 11 shows representative immunoblots and relative intensity of changes quantified by scanning densitometry.

Western blotting for Bax revealed that $24 \mathrm{~h}$ after HI, the level of this pro-apoptotic protein in the ipsilateral side increased about twofold compared to sham $(p<$ 0.001). Higher than the control level of Bax expression was also observed at $48 \mathrm{~h}$ of recovery $(p<0.05)$. In contrast, at the same time, the expression of Bax protein in the contralateral hemisphere remained unchanged. SB injection had no apparent effect on the level of this protein in the brain; however, a tendency for it to decrease in relation to vehicle treatment was observed (Fig. 11a, b).

As it is shown in Fig. 11c, d, HI significantly increased the level of $\mathrm{Bcl}-2$ in the contralateral, non-injured side pronounced at $48 \mathrm{~h}$ of recovery, compared to $\mathrm{HI}$ hemisphere $(p<0.05)$. Injection of SB after the injury did not change the HI-affected immunoreactivity.

\section{Discussion}

The principal finding in our present study is that sodium butyrate treatment exhibits brain-protective activity in a neonatal hypoxia-ischemia model. The protection afforded by SB was expressed by a clear reduction of brain damage, suppression of brain edema, and preservation of brain architecture when analyzed at 6 days after the onset of hypoxia-ischemia. Furthermore, the effect of SB was associated with substantial inhibition of HI-induced inflammation. Our findings remain in general agreement with those reported previously that deacetylase inhibitors (VPA, TSA, SB) are neuroprotective in cerebral injury models in adult rodents [3-5]. Our data also agrees with a brief paper showing neuroprotection following treatment with valproate (VPA) after HI in neonatal rat [12].

Neonatal hypoxia-ischemia triggers a series of pathophysiological processes (including loss of energy, acidosis, excitotoxicity, elevation of intracellular calcium, induction of oxidative stress, inflammation) that result in a loss of neurons and severe neurological deficits. It is generally accepted that one of the most important 

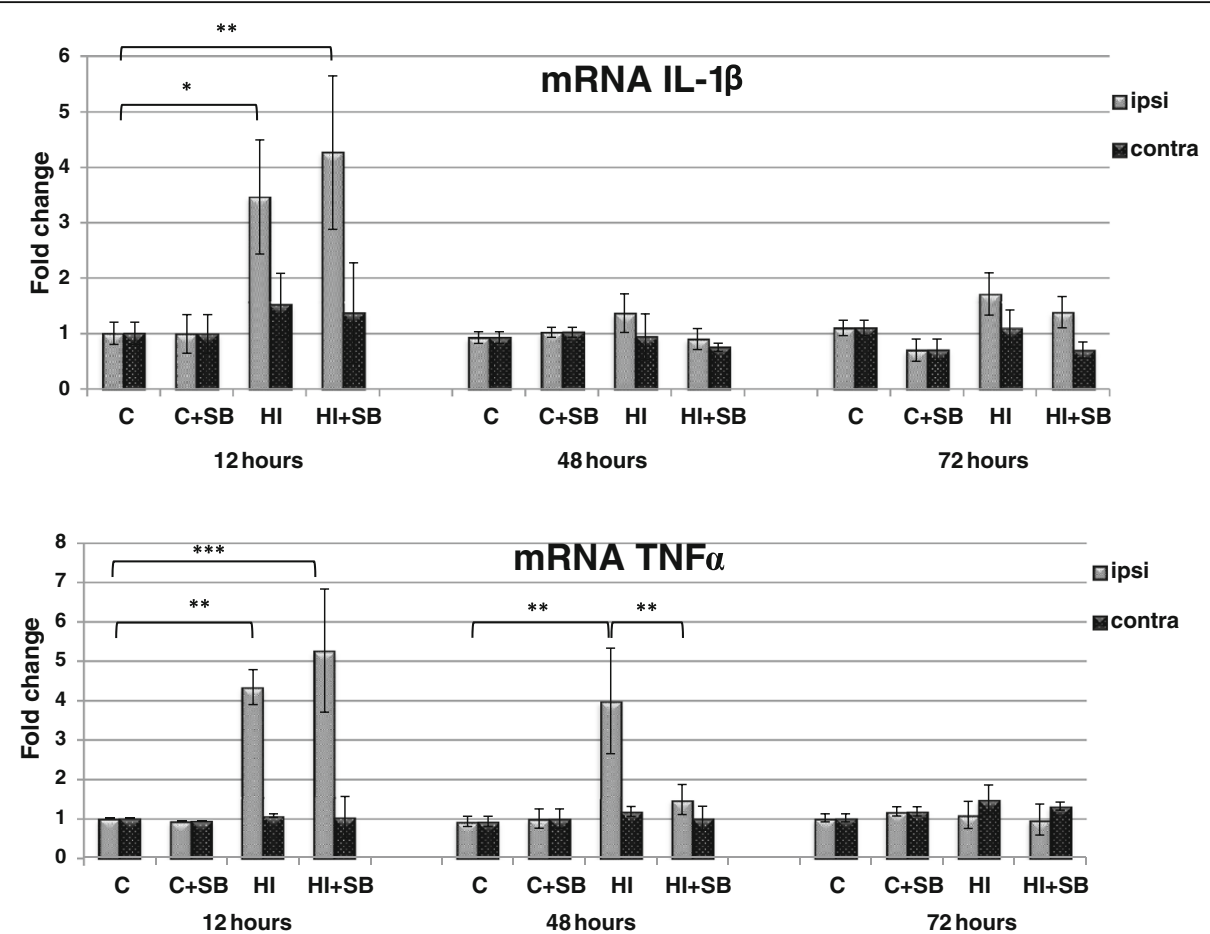

Fig. 7 Effects of SB treatment on gene expression of IL-1 $\beta$ and TNFa in the brain after neonatal HI. Seven-day-old rats (PND7) were subjected to hypoxia-ischemia followed by 12,48 , and $72 \mathrm{~h}$ of recovery. SB or vehicle was administered directly after the onset of $\mathrm{HI}$ and for 2 or 3 consecutive days (determined by the experimental paradigm). The mRNA expression was determined in the ipsilateral (injured) hemispheres as well as in the control brains. Graphs represent statistical analysis of the data from indicated experimental groups: vehicle control (C), SB-treated control (C + SB), vehicle-treated hypoxia-ischemia $(\mathrm{HI})$, and SB-treated hypoxia-ischemia $(\mathrm{HI}+\mathrm{SB})$. Note the decrease of HI-induced elevation of TNFa mRNA expression after SB treatment at $48 \mathrm{~h}$ of recovery. The values represent means \pm SD from five animals in each group. The one-way ANOVA and Bonferroni test: ${ }^{*} p<0.05,{ }^{* *} p<0.01$, and ${ }^{* *} p<0.001$. C control, ipsi ipsilateral, contra contralateral

pathogenic components of neonatal brain damage is inflammation induced by either the production of cytokines and chemokines followed by leukocyte (including monocytes and macrophages) infiltration or glial activation and proliferation [21-23]. First of all, it is in agreement that blocking the inflammatory reaction promotes neuroprotection and, in addition, has potential for use in the clinical treatment of ischemic brain injury [21, 24, 25].

Convincing evidence reveals that HDACis, among VPA, TSA and SB, are efficacious neuroprotective agents in adult cerebral injury models associated with inflammation. Administration of these compounds after the onset of stroke results in a marked reduction of microglia number, suppression of their activation, and inhibition of other inflammatory markers, which in turn lead to improved neuropathological outcome [4, 5]. In contrast to these findings, our results show that SB treatment of neonatal HI induced a paradoxical significant increase in the number of ED1-positive cells (microglia/macrophages) in the damaged ipsilateral hemisphere at 6 days after the insult, as compared to animals treated with vehicle. As demonstrated in the current study, the majority of ED-1+ cells present a positive reaction with an established marker of M2 microglia phenotype, arginase- 1 , mostly pronounced in the SB-treated rats. It may be speculated that SB facilitates conversion of M1 to M2 leading to antiinflammatory signalling and, by this, keeps microglia from acquiring a proinflammatory phenotype, and in consequence prevents tissue damage, such as that found in models of $\mathrm{AD}, \mathrm{MS}$, and neurodegeneration [26-28]. This prediction may be reinforced by the parallel decrease in the number of ED-1/IL-1 $\beta$ positive cells observed in our study. The reduced cytokine response after SB treatment, despite an increase in the number of microglia, implies that these cells are not necessarily damaging and in some conditions may alleviate harmful consequences of injury. This hypothesis remains in line with data showing that transition in the microglial response during recovery from the proinflammatory (M1) to immunomodulatory and neurotrophic response (M2) [29-32] and then maintenance of endogenous neurogenesis [33-36] may play a key role in attenuation of brain damage [37]. To confirm the role of the microglial reaction to HI injury in the developing brain and, in particular, to define the time course of M1 to M2 polarization, further studies will be needed. 

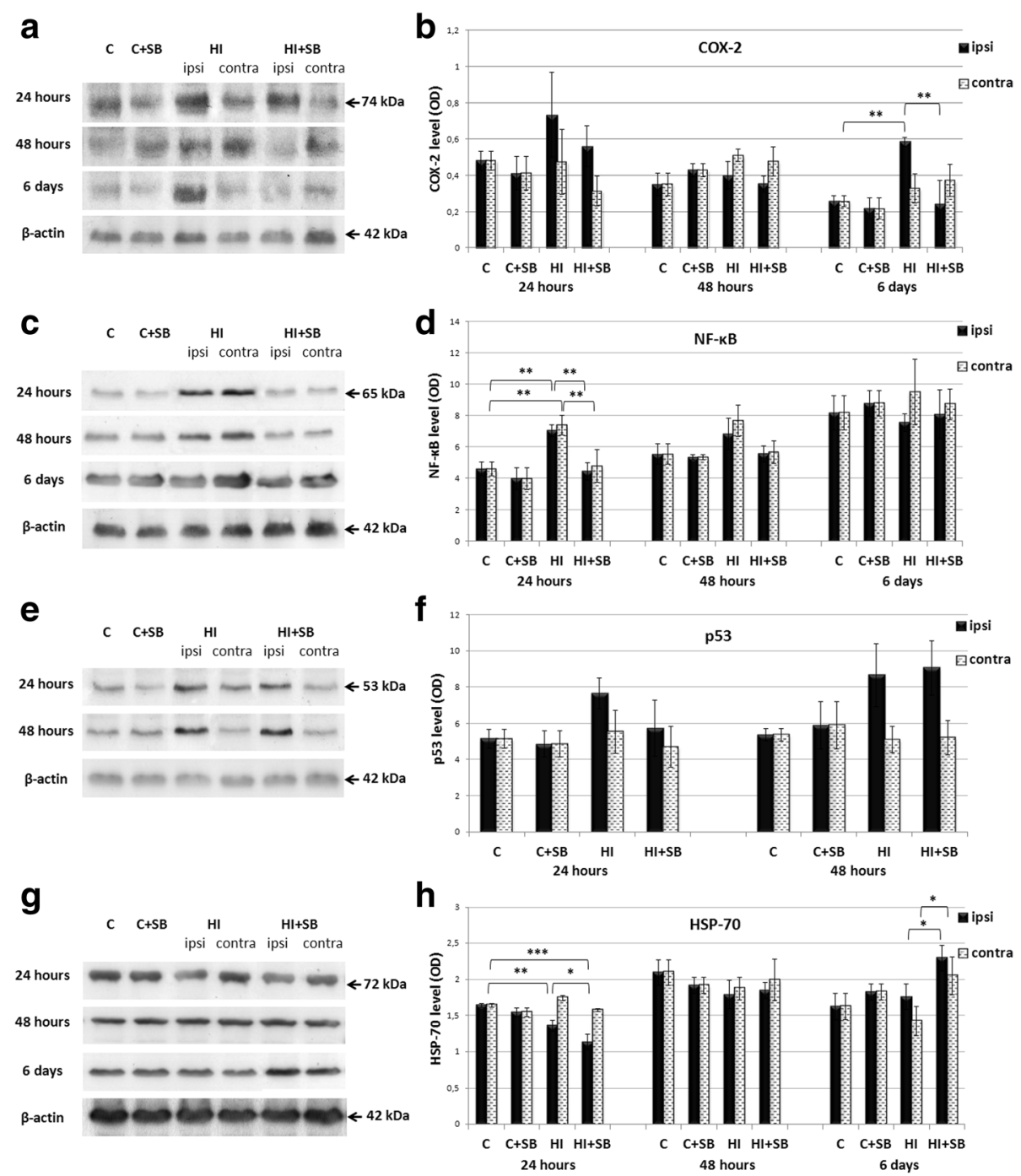

Fig. 8 Effects of SB on the expression of COX-2, NfkB, p53, and HSP70 in the brain after neonatal HI. Seven-day-old rats (PND7) were subjected to hypoxia-ischemia followed by 24 and $48 \mathrm{~h}$ and 6 days of recovery. SB or vehicle was administered directly after the onset of HI and for 2 or 5 consecutive days (determined by the experimental paradigm). Figure shows representative immunoblots of COX-2 (a), NfKB (c), p53 (e), and HSP-70 (g) protein in brain hemispheres, analyzed in four experimental groups: vehicle control (C), SB-treated control (C + SB), vehicle-treated hypoxia-ischemia $(\mathrm{HI})$, and SB-treated hypoxia-ischemia $(\mathrm{HI}+\mathrm{SB})$. The intensity of each band obtained by respective Western blotting was quantified by LKB Ultrascan XL software and normalized in relation to $\beta$-actin. Bar graphs $(\mathbf{b}, \mathbf{d}, \mathbf{f}, \mathbf{h})$ represent statistical analysis of densitometric data (OD units) from indicated experimental groups. Note the decrease of HI-induced elevation of COX-2 immunoreactivity after SB treatment at 6 days of recovery. The administration of SB also resulted in an increased expression of HSP70 protein at the same time point. The values represent means \pm SD from five animals. The one-way ANOVA and Bonferroni test: ${ }^{*} p<0.05,{ }^{* *} p<0.01$. C control, ipsi ipsilateral, contra contralateral

It is commonly known that reactive astrocytosis also appears to be a part of the hypoxia-ischemia-induced pathological processes $[38,39]$. Consistent with previous reports [30, 40, 41], we noted a delayed increase in GFAP expression accompanied with hypertrophy and cell proliferation in the ipsilateral hemisphere at 6 days after the insult, implying astrogliosis. The expression of GFAP was further markedly increased by SB treatment. However, this increase was associated with the reduction of cell population co-expressing GFAP and proinflammatory IL-1 $\beta$. It is worthy to note that SB treatment also led to diminished IL- $\beta$ production in microglia/macrophages at the same time point. This reduction of IL- $1 \beta$ expression after SB injection in glial cells parallels the attenuation of brain damage. The precise molecular mechanism responsible for the effect of SB is not known. However, apart from the number of biochemical and morphological factors functioning in concert to influence the final SB effect, accumulation of GFAP protein presented here is likely to also contribute to neuroprotection after neonatal HI. This may be supported by data showing that GFAP knock-out mice have a greater 


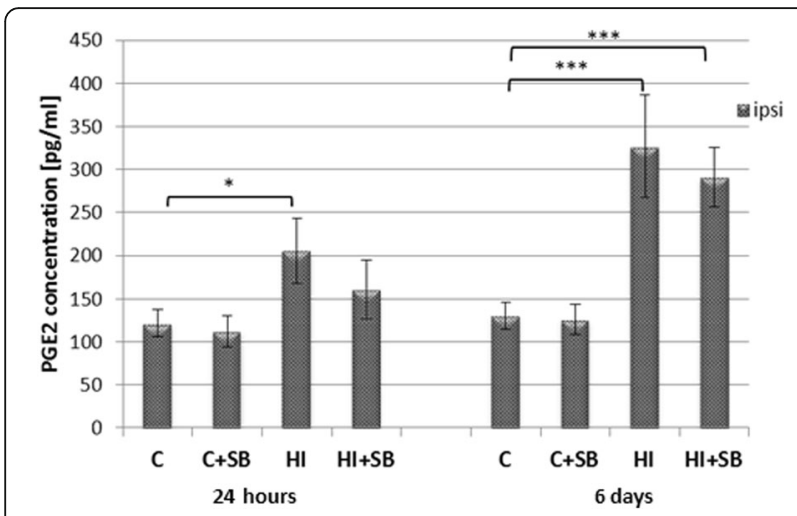

Fig. 9 The effect of SB on PGE2 concentration in the brain after neonatal HI. Seven-day-old rats (PND7) were subjected to hypoxia-ischemia followed by $24 \mathrm{~h}$ and 6 days of recovery. SB or vehicle was administered directly after the onset of $\mathrm{HI}$ and for 5 consecutive days (determined by the experimental paradigm). The PGE2 concentration was determined in the ipsilateral (injured) hemispheres as well as in the control brains. Graphs represent statistical analysis of the data from indicated experimental groups: vehicle control (C), SB-treated control (C + SB), vehicle-treated hypoxia-ischemia $(\mathrm{HI})$, and SB-treated hypoxia-ischemia (HI + SB). SB application had no effect on the HI-induced activation of PGE2 in the HI ipsilateral hemispheres. The values represent means \pm SD from five animals in each group. The one-way ANOVA and Bonferroni test: ${ }^{*} p<0.05$ and ${ }^{* * *} p<0.001$. C control, ipsi ipsilateral

susceptibility to ischemic injury [42]. Furthermore, experimental disruption of astroglial scar formation following stroke results in an increased spread of inflammation and increased lesion volume [43]. Although results obtained from adult experiments cannot be directly transferred and used as explanation for neonatal data due to

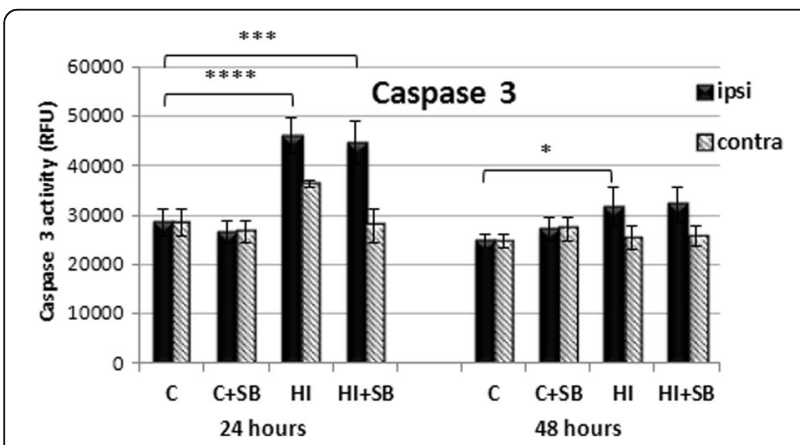

Fig. 10 The effect of SB treatment on caspase-3 activity in the brain after neonatal HI. Seven-day-old rats (PND7) were subjected to hypoxia-ischemia followed by 24 or 48 h of recovery. SB or vehicle was administered directly after the onset of $\mathrm{HI}$ and for 2 consecutive days. Bar graphs represent statistical analysis of fluorescence units estimated in four experimental groups: vehicle control (C), SB-treated control $(C+S B)$, vehicle-treated hypoxia-ischemia $(H)$, and SB-treated hypoxia-ischemia $(H I+S B)$. SB application had no effect on the $\mathrm{HI}$-induced activation of caspase- 3 in the $\mathrm{HI}$ ipsilateral hemispheres. The values represent means \pm SD from five animals. The one-way ANOVA and Bonferroni test: ${ }^{*} p<0.05,{ }^{* * *} p<0.001,{ }^{* * *} p<0.0001$ C control, ipsi ipsilateral, contra contralateral differences in the level of maturation and different ischemia model, some hypotheses may be valid in adults as well as in neonates. Nevertheless, a precise role of enhanced astrogliosis seen after SB treatment of neonatal $\mathrm{HI}$ is yet to be determined.

Cytokines are regarded as pro- or anti-inflammatory, and based on their state and/or concentration, they can be protective or harmful. Although these proteins can be found in almost any nucleated cell within the brain, such as brain endothelial cells or neurons, they are mainly produced by glial cells or by immune cells, such as helper $\mathrm{T}$ cells. Therefore, in the present study, we followed the influence of SB administration on the total content of selected cytokines correlating with the brain damage. The biological effect of these factors include stimulation and synthesis of other cytokines and prompting leukocyte infiltration, which in turn leads to the induction of neuronal injury mediators and influencing glial expression (see rev [44]). Our results, in general accordance with other reports [40], depicted a considerable alteration in the expression of IL- $1 \alpha$, IL- $1 \beta$, TNF $\alpha$, and chemokine CXCL10 in the ipsilateral hemisphere at $48 \mathrm{~h}$ after $\mathrm{HI}$ compared to the control one. In line with this, we also observed a significant enhancement in IL-1 $\beta$ and TNF $\alpha$ mRNA level estimated $12 \mathrm{~h}$ following the insult. In addition to these early modifications, IL-1 $\beta$ and chemokine CXCL10 protein expression presented a delayed increase after 6 days of recovery suggesting ongoing inflammation. This is in agreement with reported elevation in mRNA and protein level of IL- $1 \beta$ even at 14 days after HI $[45,46]$. Treatment with SB suppressed significantly HI-induced upregulation of chemokine CXCL10 at $48 \mathrm{~h}$ and IL-1 $\beta$ at 6 days after HI. In the case of IL- $1 \alpha$ and TNF $\alpha$, the effect of SB was presented only by a non-significant decrease in their level $48 \mathrm{~h}$ after the insult, despite a sole, clear reduction in TNF $\alpha$ mRNA expression in the same condition. Probably both factors do not play a prominent role in the protective action mediated by this inhibitor.

The reduction of IL-1 $\beta$ expression presented in our study seems to be particularly important and strongly supported by a number of data showing that downregulation of this cytokine plays a neuroprotective function in the development of $\mathrm{HI}$ encephalopathy $[22,29,47,48]$. According to research, the decrease of IL-1 $\beta$ production can reverse cell swelling, brain edema, and neurologic function deficiencies induced by HI [49].

Despite the number of reports focusing on the role of IL- $1 \beta$, only a few data are available on the potential role of chemokines in the development of HIE [50]. It was found in a neonatal mouse study of $\mathrm{HI}$ injury that mRNA expression of chemokines precedes infiltration of immune cells into the brain, thus proving their relevance in the inflammatory response. It is therefore reasonable 

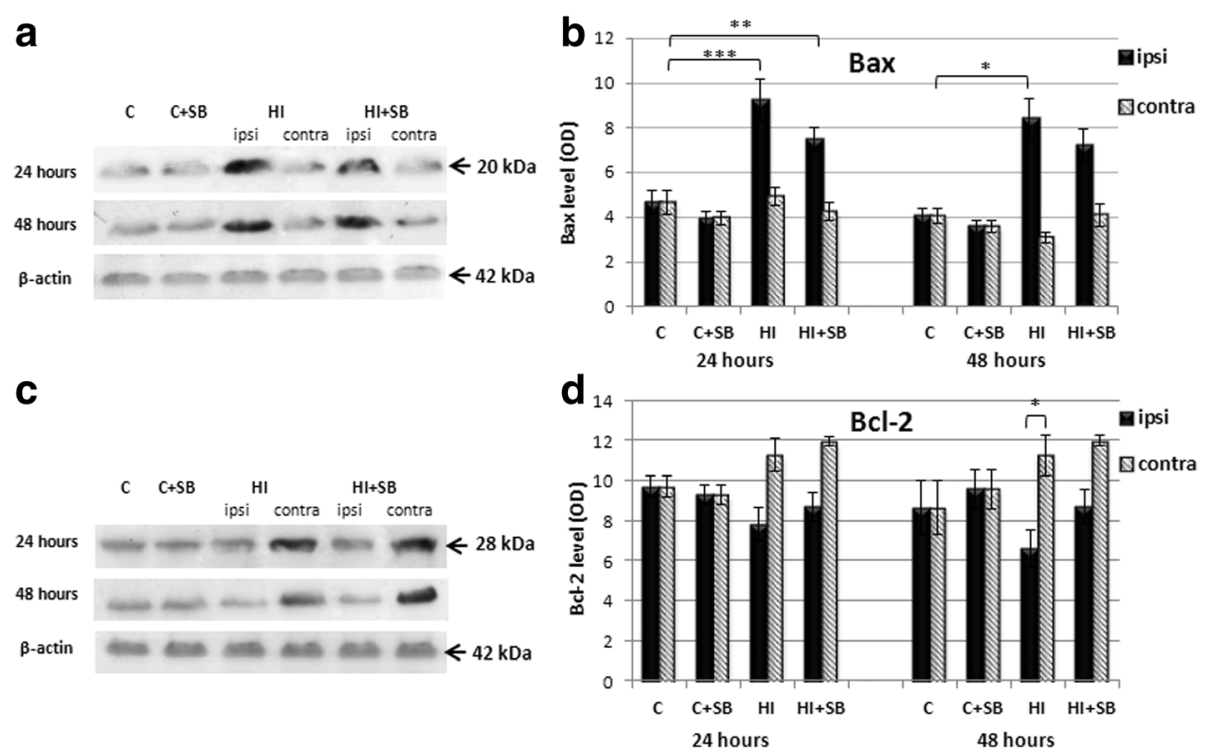

Fig. 11 The effect of SB treatment on pro-apoptotic and anti-apoptotic protein levels in the brain after neonatal HI. Seven-day-old rats (PND7) were subjected to hypoxia-ischemia followed by 24 or $48 \mathrm{~h}$ of recovery. SB or vehicle was administered directly after the onset of $\mathrm{HI}$ and for 2 consecutive days. Figure shows representative immunoblots of pro-apoptotic Bax and anti-apoptotic Bcl-2 protein levels ( $\mathbf{a}$, $\mathbf{c})$ in brain hemispheres, analyzed in four experimental groups: vehicle control (C), SB-treated control (C + SB), vehicle-treated hypoxia-ischemia (HI), and SB-treated hypoxia-ischemia $(\mathrm{HI}+\mathrm{SB})$. The intensity of each band obtained by Western blotting was quantified by LKB Ultrascan XL software and normalized in relation to $\beta$-actin. Bar graphs $(\mathbf{b}$, $\mathbf{d})$ represent statistical analysis of densitometric data from indicated experimental groups. Note the increased expression of Bax in the ipsilateral and $\mathrm{BCl}-2$ in the contralateral side after $\mathrm{HI}$. The values represent means \pm SD of five animals in each experimental group. The one-way ANOVA and Bonferroni test: ${ }^{*} p<0.05,{ }^{* *} p<0.01$ and ${ }^{* * *} p<0.001$. C control, ipsi ipsilateral, contra contralateral

to speculate that the reduction of CXCL10 expression observed in the present study participates, at least partially, in the beneficial action of SB. On the other hand, chemokines attract mesenchymal stem cells to home at the lesion site [51]. Hence, immunomodulatory intervention may have a negative effect upon specific aspects of neurogenesis and thus brain regeneration. Therefore, the question arises if the protective abilities will outweigh the potentially harmful consequences.

It has been suggested that in terms of anti-inflammatory effects, inhibition of COX-2 and subsequent reduction of prostaglandin E2 (PGE2) generation, a major downstream product of COX-2 enzymatic activity, can lead to attenuation of ischemic injury in adult rodents [52-54]. As demonstrated in the current study, SB administration decreased the HI-induced elevated COX-2 expression in the damaged ipsilateral hemisphere. This observation may be related to the reduced level of pro-inflammatory IL-1 $\beta$ at the same time point, as demonstrated by Neeb et al. [55]. Unexpectedly, the decreased expression of COX-2 after SB treatment seen 6 days post-HI does not result in diminished generation of PGE2. Moreover, the fact that COX-2 and PGE2 levels do not correlate in animal models of induced inflammation is also an interesting finding [56]. The lack of this correlation suggests that not COX-2 but COX-1 isoform may be expressed and be responsible for maintaining the PGE2 production under brain ischemia $[54,57-59]$. Nevertheless, the reason for SB suppression of COX-2 and not PGE2 level in our study is unclear at present and should be explored in the future. Particular attention should be paid to the complexity of enzymatic pathways embedded in PGE2 synthesis and degradation, rather than focusing only on COX-1 and COX-2 concentration. In this context, it is noteworthy that PGE2 under defined conditions may not only contribute to brain damage but rather affect and modulate neuronal function in a positive way through the regulation of microcirculation and synaptic functions [60, 61].

Several findings indicate that inhibitors of histone deacetylases may also modify diverse targets including, among others, transcription factors such as NFkB and $p$ 53 , the HSP family of proteins, and apoptosis-related genes $[4,62,63]$.

A number of reports point to the damaging role of activated by brain ischemia nuclear factor NFKB. This is supported by studies showing that inhibition of NFkB activation after ischemia in adult rodents prevents brain damage in the insulted hemisphere via inhibition of cytokine response [64-67]. However, our findings revealed that following neonatal hypoxiaischemia, the expression of $\mathrm{NFKB}$ increased significantly in both hemispheres, ipsi- and contralateral, 
despite tissue alterations not being observed in the hypoxic, uninjured side. Moreover, in both hemispheres, the level of $\mathrm{NF}_{\mathrm{K} B}$ returned to the control value after $\mathrm{SB}$ treatment. Thus, the question arises whether the response of $\mathrm{Nf} \kappa \mathrm{B}$ to $\mathrm{SB}$ may constitute part of the defense process against $\mathrm{HI}$-induced damage in the ipsilateral side. It is worthy to mention that probably the basal level of NFKB is sufficient for conditions required for neonatal brain development.

An additional suggested factor by which HDACis are reported to mediate neuroprotection in adult cerebral injury models includes HSP70 [68-71]. HSP70 besides functioning as a key member of molecular chaperon system has also been assigned an anti-apoptotic function, although failure to detect protection against apoptosis in neurons overexpressing HSP70 also has been reported [72]. Nevertheless, most studies describe increased expression of HSP70 as a neuroprotective mechanism in adult rodents after $\mathrm{MCAO}[3,73,74]$, as well as after neonatal HI [75]. The suggested influence of HSP70 action includes inhibition of nuclear transcription factor-NFKB. In contrast to high expression of HSP70 at 12-48 h found by Van den Tweel [75] in the damaged HI hemisphere, our present results show significant reduction of this protein level at the same time point regardless of exposure to SB. Additionally, the changes in HSP70 expression observed in our studies do not parallel alterations seen in the level of $\mathrm{Nf} \kappa \mathrm{B}$. The major difference with our study is that we used P7 vs P12 rats and a different time of hypoxia-60 vs $90 \mathrm{~min}$ of hypoxia insult used by Van den Tweel [75]. The reason for the loss of HSP70 may be due to a low rate of its synthesis or increased activity of proteases able to digest HSP70. Also, our results are more clearly in agreement with Sun et al. [76], showing that HSP70 is only slightly altered, if at all, in P7 neurons after HI. Interestingly, SB treatment caused elevation of HSP70 expression in both brain hemispheres 6 days post-HI. It seems that such delayed response detected in both hemispheres has to be insult independent. It may be also considered that induction of HSP70 after SB treatment may facilitate neuroplasticity during recovery time and improve learning processes [77].

We also tested if SB-induced neuroprotection in the HI neonatal brain involves changes in the expression of p53-apoptosis regulating transcription factor. The implication that p53 plays a role in the response that follows a hypoxic-ischemic insult stems from the observation that pifithrin alpha, an inhibitor of p53, decreases the number of apoptotic cells in the ischemic brain [78]. In contrast to the robust upregulation of p53 detected in the adult ischemia model in rodents and inhibition of p53 protein levels by SB [4], HI induced in neonates with/or without SB treatment did not show any significant effect. Thus, p53 seems to not contribute to the protective effect of SB.

Finally, our results revealed no apparent effect on caspase-3 activation, as well as on expression of antiapoptotic proteins $\mathrm{Bcl}-2$ and pro-apoptotic Bax. Therefore, these targets probably do not mediate SB-induced neuroprotection.

\section{Conclusions}

In conclusion, we demonstrated that $\mathrm{SB}$, an inhibitor of histone deacetylases, has significant neuroprotective abilities in a model of HI-induced neonatal brain injury. However, we were incapable of finding the precise mechanism by which SB exerts its actions. The mechanisms associated with the outcome of SB were not in agreement with those reported in adult cerebral injury studies. Nevertheless, the present results imply that some effects may be mediated by suppression of inflammation. Based on the findings obtained in our laboratory [10], it is also tempting to speculate that the delayed neuroprotective action may be mediated in part by increased proliferation and/or neurogenesis.

\section{Abbreviations}

AD: Alzheimer's disease; ANOVA: Analysis of variance; Arg-1: Arginase 1; BCl-2: B-cell lymphoma 2; C: Control; CONTRA: Contralateral hemisphere; COX2: Cyclooxygenase-2; CXCL10 (IP-10): C-X-C motif chemokine 10; ED1

(CD68): Cluster of Differentiation 68; ELISA: Enzyme-linked immunosorbent assay; GFAP: Glial fibrillary acidic protein; HDACi: Histone deacetylase inhibitor; HE: Hematoxylin and eosin stain; HI: Hypoxia-ischemia; HSP70: Heat shock protein 70; IFN-ү: Interferon gamma; IL-12: Interleukin 12; IL-1a: Interleukin 1 alpha; IL-1 $\beta$ : Interleukin 1 beta; IL-2: Interleukin 2; IL-4: Interleukin 4; IPSI: Ipsilateral hemisphere; MCAO: Middle cerebral artery occlusion; NFKB: Nuclear factor kappa-light-chain-enhancer of activated B cells; PBS: Phosphate-buffered saline; PFA: Paraformaldehyde; PGE2: Prostaglandin E2; PMSF: Phenylmethylsulfonyl fluoride; PND7: Postnatal day 7; qRT-

PCR: Quantitative reverse transcriptase real-time polymerase chain reaction; SAHA: Suberoylanilide hydroxamic acid; SB: Sodium butyrate; SDHA: Succinate dehydrogenase complex flavoprotein subunit A; SDS-PAGE: Sodium dodecyl sulfate polyacrylamide gel electrophoresis; TNFa: Tumor necrosis factor alpha; TSA: Trichostatin A; VPA: Valproate

\section{Acknowledgements}

Not applicable.

\section{Funding}

This work was supported by the National Science Centre, Poland grant nos. 2012/05/B/NZ3/00436, 2014/15/B/NZ4/01875, and 2015/17/N/NZ7/00969. The funders had no role in the study design, data collection and analysis, decision to publish, or preparation of the manuscript.

\section{Availability of data and materials}

The datasets generated and/or analyzed during the current study are available from the corresponding author on reasonable request.

\section{Authors' contributions}

$\mathrm{JJ}$ and $\mathrm{MN}-\mathrm{Z}$ equally performed, analysed, and interpreted all of the data, as well as contributed in writing the manuscript. JS prepared figures and contributed in writing the manuscript. TZ interpreted the data and was a major contributor in writing the manuscript. All authors read and approved the final manuscript. 


\section{Consent for publication}

Not applicable.

\section{Ethics approval and consent to participate}

This study did not utilize any human participants, human data, or human tissue. All animal experiments were conducted according to a protocol approved by the IV Local Ethics Committee for Animal Experimentation in Warsaw (83/2015).

Received: 20 July 2016 Accepted: 1 February 2017

Published online: 10 February 2017

\section{References}

1. Glozak MA, Sengupta N, Zhang X, Seto E. Acetylation and deacetylation of non-histone proteins. Gene. 2005;363:15-23.

2. Haberland M, Montgomery RL, Olson EN. The many roles of histone deacetylases in development and physiology: implications for disease and therapy. Nat Rev Genet. 2009;10:32-42.

3. Ren $\mathrm{M}$, Leng $\mathrm{Y}$, Jeong $\mathrm{M}$, Leeds PR, Chuang D-M. Valproic acid reduces brain damage induced by transient focal cerebral ischemia in rats: potential roles of histone deacetylase inhibition and heat shock protein induction. J Neurochem. 2004;89:1358-67.

4. Kim HJ, Rowe M, Ren M, Hong J-S, Chen P-S, Chuang D-M. Histone deacetylase inhibitors exhibit anti-inflammatory and neuroprotective effects in a rat permanent ischemic model of stroke: multiple mechanisms of action. J Pharmacol Exp Ther. 2007;321:892-901.

5. Kim HJ, Leeds P, Chuang D-M. The HDAC inhibitor, sodium butyrate, stimulates neurogenesis in the ischemic brain. J Neurochem. 2009;110: 1226-40.

6. Chuang D-M, Leng Y, Marinova Z, Kim H-J, Chiu C-T. Multiple roles of HDAC inhibition in neurodegenerative conditions. Trends Neurosci. 2009:32:591-601.

7. Liu XS, Chopp M, Kassis H, Jia LF, Hozeska-Solgot A, Zhang RL, et al. Valproic acid increases white matter repair and neurogenesis after stroke. Neuroscience. 2012;220:313-21.

8. Endres M, Meisel A, Biniszkiewicz D, Namura S, Prass K, Ruscher K, et al. DNA methyltransferase contributes to delayed ischemic brain injury. J Neurosci. 2000;20:3175-81.

9. Gräff J, Kim D, Dobbin MM, Tsai L-H. Epigenetic regulation of gene expression in physiological and pathological brain processes. Physiol Rev. 2011;91:603-49.

10. Ziemka-Nalecz M, Jaworska J, Sypecka J, Polowy R, Filipkowski RK, Zalewska T. Sodium Butyrate, a Histone Deacetylase Inhibitor, Exhibits Neuroprotective/Neurogenic Effects in a Rat Model of Neonatal HypoxiaIschemia. Mol Neurobiol. 2016. doi:10.1007/s12035-016-0049-2. in press

11. George S, Kadam SD, Irving ND, Markowitz GJ, Raja S, Kwan A, et al. Impact of trichostatin $A$ and sodium valproate treatment on post-stroke neurogenesis and behavioral outcomes in immature mice. Front Cell Neurosci. 2013;7:123.

12. Kabakus N, Ay I, Aysun S, Söylemezoglu F, Ozcan A, Celasun B. Protective effects of valproic acid against hypoxic-ischemic brain injury in neonatal rats. J Child Neurol. 2005;20:582-7.

13. Fleiss B, Nilsson MKL, Blomgren K, Mallard C. Neuroprotection by the histone deacetylase inhibitor trichostatin $A$ in a model of lipopolysaccharide-sensitised neonatal hypoxic-ischaemic brain injury. J Neuroinflammation. 2012;9:70.

14. Dammann O, Ferriero D, Gressens P. Neonatal encephalopathy or hypoxicischemic encephalopathy? Appropriate terminology matters. Pediatr Res. 2011;70:1-2.

15. Ferriero DM. Neonatal brain injury. N Engl J Med. 2004;351:1985-95.

16. van Handel $M$, Swaab $H$, de Vries LS, Jongmans MJ. Long-term cognitive and behavioral consequences of neonatal encephalopathy following perinatal asphyxia: a review. Eur J Pediatr. 2007;166:645-54.

17. Volpe JJ. Perinatal brain injury: from pathogenesis to neuroprotection. Ment Retard Dev Disabil Res Rev. 2001;7:56-64.

18. Rice JE, Vannucci RC, Brierley JB. The influence of immaturity on hypoxicischemic brain damage in the rat. Ann Neurol. 1981;9:131-41.

19. Vannucci RC, Vannucci SJ. A model of perinatal hypoxic-ischemic brain damage. Ann N Y Acad Sci. 1997:835:234-49.

20. Vannucci RC, Vannucci SJ. Perinatal hypoxic-ischemic brain damage: evolution of an animal model. Dev Neurosci. 2005;27:81-6.
21. McRae A, Gilland E, Bona E, Hagberg H. Microglia activation after neonatal hypoxic-ischemia. Brain Res Dev Brain Res. 1995;84:245-52.

22. Hagberg H, Gilland E, Bona E, Hanson LA, Hahin-Zoric M, Blennow M, et al. Enhanced expression of interleukin (IL)-1 and IL-6 messenger RNA and bioactive protein after hypoxia-ischemia in neonatal rats. Pediatr Res. 1996; 40:603-9.

23. Liu F, McCullough LD. Inflammatory responses in hypoxic ischemic encephalopathy. Acta Pharmacol Sin. 2013;34:1121-30.

24. Carty ML, Wixey JA, Colditz PB, Buller KM. Post-insult minocycline treatment attenuates hypoxia-ischemia-induced neuroinflammation and white matter injury in the neonatal rat: a comparison of two different dose regimens. Int J Dev Neurosci Off J Int Soc Dev Neurosci. 2008;26:477-85.

25. Tang Y, Wu P, Su J, Xiang J, Cai D, Dong Q. Effects of Aquaporin-4 on edema formation following intracerebral hemorrhage. Exp Neurol. 2010;223:485-95.

26. Cipriani R, Villa P, Chece G, Lauro C, Paladini A, Micotti E, et al. CX3CL1 is neuroprotective in permanent focal cerebral ischemia in rodents. J Neurosci Off J Soc Neurosci. 2011;31:16327-35.

27. Fuhrmann M, Bittner T, Jung CKE, Burgold S, Page RM, Mitteregger G, et al. Microglial $\mathrm{Cx} 3 \mathrm{cr} 1$ knockout prevents neuron loss in a mouse model of Alzheimer's disease. Nat Neurosci. 2010;13:411-3.

28. Koning N, Bö L, Hoek RM, Huitinga I. Downregulation of macrophage inhibitory molecules in multiple sclerosis lesions. Ann Neurol. 2007;62:504-14.

29. Bonestroo HJC, Nijboer CHA, van Velthoven CTJ, Kavelaars A, Hack CE, van Bel F, et al. Cerebral and hepatic inflammatory response after neonatal hypoxia-ischemia in newborn rats. Dev Neurosci. 2013;35:197-211.

30. Shrivastava K, Llovera G, Recasens M, Chertoff M, Giménez-Llort L, Gonzalez $B$, et al. Temporal expression of cytokines and signal transducer and activator of transcription factor 3 activation after neonatal hypoxia/ischemia in mice. Dev Neurosci. 2013;35:212-25.

31. Soehnlein O, Lindbom L. Phagocyte partnership during the onset and resolution of inflammation. Nat Rev Immunol. 2010;10:427-39.

32. Varin A, Gordon S. Alternative activation of macrophages: immune function and cellular biology. Immunobiology. 2009;214:630-41.

33. Aarum J, Sandberg K, Haeberlein SLB, Persson MAA. Migration and differentiation of neural precursor cells can be directed by microglia. Proc Natl Acad Sci U S A. 2003;100:15983-8.

34. Starossom SC, Mascanfroni ID, Imitola J, Cao L, Raddassi K, Hernandez SF, et al. Galectin-1 deactivates classically activated microglia and protects from inflammation-induced neurodegeneration. Immunity. 2012;37:249-63.

35. Hu X, Li P, Guo Y, Wang H, Leak RK, Chen S, et al. Microglia/macrophage polarization dynamics reveal novel mechanism of injury expansion after focal cerebral ischemia. Stroke J Cereb Circ. 2012;43:3063-70.

36. Hu X, Leak RK, Shi Y, Suenaga J, Gao Y, Zheng P, et al. Microglial and macrophage polarization-new prospects for brain repair. Nat Rev Neurol. 2015;11:56-64.

37. Cikla U, Chanana V, Kintner DB, Covert L, Dewall T, Waldman A, et al. Suppression of microglia activation after hypoxia-ischemia results in age-dependent improvements in neurologic injury. J Neuroimmunol. 2016;291:18-27.

38. Sen E, Levison SW. Astrocytes and developmental white matter disorders. Ment Retard Dev Disabil Res Rev. 2006;12:97-104.

39. Sullivan SM, Björkman ST, Miller SM, Colditz PB, Pow DV. Morphological changes in white matter astrocytes in response to hypoxia/ischemia in the neonatal pig. Brain Res. 2010;1319:164-74.

40. Bona E, Andersson A-L, Blomgren K, Gilland E, Puka-Sundvall M, Gustafson K, et al. Chemokine and inflammatory cell response to hypoxia-ischemia in immature rats. Pediatr Res. 1999;45:500-9.

41. Burtrum D, Silverstein FS. Hypoxic-ischemic brain injury stimulates glial fibrillary acidic protein mRNA and protein expression in neonatal rats. Exp Neurol. 1994;126:112-8.

42. Nawashiro H, Brenner M, Fukui S, Shima K, Hallenbeck JM. High susceptibility to cerebral ischemia in GFAP-null mice. J Cereb Blood Flow Metab Off J Int Soc Cereb Blood Flow Metab. 2000:20:1040-4.

43. Li L, Lundkvist A, Andersson D, Wilhelmsson U, Nagai N, Pardo AC, et al. Protective role of reactive astrocytes in brain ischemia. J Cereb Blood Flow Metab Off J Int Soc Cereb Blood Flow Metab. 2008;28:468-81.

44. Rocha-Ferreira E, Hristova M. Antimicrobial peptides and complement in neonatal hypoxia-ischemia induced brain damage. Front Immunol. 2015;6:56.

45. Sun Y, Calvert JW, Zhang JH. Neonatal hypoxia/ischemia is associated with decreased inflammatory mediators after erythropoietin administration. Stroke J Cereb Circ. 2005;36:1672-8. 
46. Hedtjärn M, Leverin A-L, Eriksson K, Blomgren K, Mallard C, Hagberg H. Interleukin-18 involvement in hypoxic-ischemic brain injury. J Neurosci Off J Soc Neurosci. 2002;22:5910-9.

47. Martin D, Chinookoswong N, Miller G. The interleukin-1 receptor antagonist (rhIL-1 ra) protects against cerebral infarction in a rat model of hypoxiaischemia. Exp Neurol. 1994;130:362-7.

48. Hong YH, Park CW, Kim HS, Won KC, Kim YW, Lee CK. Effects of hypoxia/ ischemia on catabolic mediators of cartilage in a human chondrocyte, SW1353. Biochem Biophys Res Commun. 2013;431:478-83.

49. Liu S, Zhu S, Zou Y, Wang T, Fu X. Knockdown of IL-1 improves hypoxiaischemia brain associated with IL-6 up-regulation in cell and animal models. Mol Neurobiol. 2015;51:743-52.

50. Mirabelli-Badenier M, Braunersreuther V, Viviani GL, Dallegri F, Quercioli A, Veneselli E, et al. CC and CXC chemokines are pivotal mediators of cerebral injury in ischaemic stroke. Thromb Haemost. 2011;105:409-20.

51. Donega V, Nijboer CH, Braccioli L, Slaper-Cortenbach I, Kavelaars A, van Bel $F$, et al. Intranasal administration of human MSC for ischemic brain injury in the mouse: in vitro and in vivo neuroregenerative functions. PloS One. 2014; 9:e112339.

52. Sugimoto K, ladecola C. Delayed effect of administration of COX-2 inhibitor in mice with acute cerebral ischemia. Brain Res. 2003;960:273-6.

53. Andreasson K. Emerging roles of PGE2 receptors in models of neurological disease. Prostaglandins Other Lipid Mediat. 2010;91:104-12.

54. Candelario-Jalil E, González-Falcón A, García-Cabrera M, Álvarez D, Al-Dalain S, Martínez G, et al. Assessment of the relative contribution of COX-1 and COX-2 isoforms to ischemia-induced oxidative damage and neurodegeneration following transient global cerebral ischemia. J Neurochem. 2003;86:545-55.

55. Neeb L, Hellen P, Boehnke C, Hoffmann J, Schuh-Hofer S, Dirnagl U, et al. IL-1 $\beta$ stimulates COX-2 dependent PGE2 synthesis and CGRP release in rat trigeminal ganglia cells. PloS One. 2011;6:e17360.

56. Inoue W, Matsumura K, Yamagata K, Takemiya T, Shiraki T, Kobayashi S. Brain-specific endothelial induction of prostaglandin $E(2)$ synthesis enzymes and its temporal relation to fever. Neurosci Res. 2002;44:51-61.

57. Choi S-H, Langenbach R, Bosetti F. Genetic deletion or pharmacological inhibition of cyclooxygenase-1 attenuate lipopolysaccharide-induced inflammatory response and brain injury. FASEB J Off Publ Fed Am Soc Exp Biol. 2008;22:1491-501.

58. Moore AH, Olschowka JA, Williams JP, Okunieff P, O'Banion MK. Regulation of prostaglandin E2 synthesis after brain irradiation. Int J Radiat Oncol Biol Phys. 2005;62:267-72.

59. Pepicelli O, Fedele E, Berardi M, Raiteri M, Levi G, Greco A, et al. Cyclooxygenase-1 and -2 differently contribute to prostaglandin E2 synthesis and lipid peroxidation after in vivo activation of $\mathrm{N}$-methyl-D-aspartate receptors in rat hippocampus. J Neurochem. 2005;93:1561-7.

60. Haydon PG, Carmignoto G. Astrocyte control of synaptic transmission and neurovascular coupling. Physiol Rev. 2006;86:1009-31.

61. Taniguchi $\mathrm{H}$, Anacker C, Wang Q, Andreasson K. Protection by vascular prostaglandin E2 signaling in hypoxic-ischemic encephalopathy. Exp Neurol. 2014;255:30-7.

62. Bolden JE, Peart MJ, Johnstone RW. Anticancer activities of histone deacetylase inhibitors. Nat Rev Drug Discov. 2006;5:769-84.

63. Spange $\mathrm{S}$, Wagner $\mathrm{T}$, Heinzel $\mathrm{T}$, Krämer $\mathrm{OH}$. Acetylation of non-histone proteins modulates cellular signalling at multiple levels. Int J Biochem Cell Biol. 2009;41:185-98.

64. Buchan AM, Li H, Blackburn B. Neuroprotection achieved with a novel proteasome inhibitor which blocks NF-kappaB activation. Neuroreport. 2000; 11:427-30.

65. Hill WD, Hess DC, Carroll JE, Wakade CG, Howard EF, Chen Q, et al. The NFkappaB inhibitor diethyldithiocarbamate (DDTC) increases brain cell death in a transient middle cerebral artery occlusion model of ischemia. Brain Res Bull. 2001;55:375-86.

66. Kim S-W, Jeong J-Y, Kim HJ, Seo J-S, Han P-L, Yoon S-H, et al. Combination treatment with ethyl pyruvate and aspirin enhances neuroprotection in the postischemic brain. Neurotox Res. 2010;17:39-49.

67. Chang Y-C, Huang C-C. Perinatal brain injury and regulation of transcription Curr Opin Neurol. 2006;19:141-7.

68. Shein NA, Grigoriadis N, Alexandrovich AG, Simeonidou C, Lourbopoulos A, Polyzoidou E, et al. Histone deacetylase inhibitor ITF2357 is neuroprotective, improves functional recovery, and induces glial apoptosis following experimental traumatic brain injury. FASEB J Off Publ Fed Am Soc Exp Biol. 2009;23:4266-75.

69. Choi Y-J, Kim NH, Lim MS, Lee HJ, Kim SS, Chun W. Geldanamycin attenuates 3-nitropropionic acid-induced apoptosis and JNK activation through the expression of HSP 70 in striatal cells. Int J Mol Med. 2014;34:24-34.

70. Yildirim F, Gertz K, Kronenberg G, Harms C, Fink KB, Meisel A, et al. Inhibition of histone deacetylation protects wildtype but not gelsolindeficient mice from ischemic brain injury. Exp Neurol. 2008;210:531-42.

71. Yakovlev A, Khafizova M, Abdullaev Z, Loukinov D, Kondratyev A. Epigenetic regulation of caspase-3 gene expression in rat brain development. Gene. 2010;450:103-8.

72. Mailhos C, Howard MK, Latchman DS. Heat shock proteins hsp90 and hsp70 protect neuronal cells from thermal stress but not from programmed cell death. J Neurochem. 1994;63:1787-95.

73. Faraco G, Pancani T, Formentini L, Mascagni P, Fossati G, Leoni F, et al. Pharmacological inhibition of histone deacetylases by suberoylanilide hydroxamic acid specifically alters gene expression and reduces ischemic injury in the mouse brain. Mol Pharmacol. 2006;70:1876-84.

74. Rajdev S, Hara K, Kokubo Y, Mestril R, Dillmann W, Weinstein PR, et al. Mice overexpressing rat heat shock protein 70 are protected against cerebral infarction. Ann Neurol. 2000;47:782-91.

75. van den Tweel ERW, Kavelaars A, Lombardi MS, Nijboer CHA, Groenendaal F, van Bel F, et al. Bilateral molecular changes in a neonatal rat model of unilateral hypoxic-ischemic brain damage. Pediatr Res. 2006;59:434-9.

76. Sun X, Crawford R, Liu C, Luo T, Hu B. Development-dependent regulation of molecular chaperones after hypoxia-ischemia. Neurobiol Dis. 2015;82: 123-31.

77. Lin Y-W, Yang H-W, Min M-Y, Chiu T-H. Heat-shock pretreatment prevents suppression of long-term potentiation induced by scopolamine in rat hippocampal CA1 synapses. Brain Res. 2004;999:222-6.

78. Leker RR, Aharonowiz M, Greig NH, Ovadia H. The role of p53-induced apoptosis in cerebral ischemia: effects of the p53 inhibitor pifithrin alpha. Exp Neurol. 2004:187:478-86.

\section{Submit your next manuscript to BioMed Central and we will help you at every step:}

- We accept pre-submission inquiries

- Our selector tool helps you to find the most relevant journal

- We provide round the clock customer support

- Convenient online submission

- Thorough peer review

- Inclusion in PubMed and all major indexing services

- Maximum visibility for your research

Submit your manuscript at www.biomedcentral.com/submit
C Biomed Central 